\title{
Examining the Impact of Treatment Fidelity on Client Outcomes in a Statewide Implementation of Parent-Child Interaction Therapy
}

\author{
Mira D H Snider \\ West Virginia University, mdh0054@mix.wvu.edu
}

Follow this and additional works at: https://researchrepository.wvu.edu/etd

Part of the Child Psychology Commons, and the Clinical Psychology Commons

\author{
Recommended Citation \\ Snider, Mira D H, "Examining the Impact of Treatment Fidelity on Client Outcomes in a Statewide \\ Implementation of Parent-Child Interaction Therapy" (2019). Graduate Theses, Dissertations, and Problem \\ Reports. 3929. \\ https://researchrepository.wvu.edu/etd/3929
}

This Thesis is protected by copyright and/or related rights. It has been brought to you by the The Research Repository @ WVU with permission from the rights-holder(s). You are free to use this Thesis in any way that is permitted by the copyright and related rights legislation that applies to your use. For other uses you must obtain permission from the rights-holder(s) directly, unless additional rights are indicated by a Creative Commons license in the record and/ or on the work itself. This Thesis has been accepted for inclusion in WVU Graduate Theses, Dissertations, and Problem Reports collection by an authorized administrator of The Research Repository @ WVU. For more information, please contact researchrepository@mail.wvu.edu. 
Examining the Impact of Treatment Fidelity on Client Outcomes in a Statewide Implementation of Parent-Child Interaction Therapy

Mira D. H. Snider, B.S.

\author{
Thesis submitted \\ to the Eberly College of Arts and Sciences \\ at West Virginia University \\ in partial fulfillment of the requirements for the degree of \\ Master of Science in \\ Psychology
}

Amy D. Herschell, Ph.D., Chair

Aaron Metzger, Ph.D.

Claire St. Peter, Ph.D.

Department of Psychology

Morgantown, West Virginia

2018

Keywords: treatment fidelity, adherence, competence, parent training, externalizing behavior Copyright 2019 Mira D. H. Snider 


\begin{abstract}
Examining the Impact of Treatment Fidelity on Client Outcomes in a Statewide Implementation of Parent-Child Interaction Therapy
\end{abstract}

Mira D. H. Snider

Clinician treatment fidelity, consisting of treatment adherence and clinician competence, is commonly assessed during the implementation of evidence-based treatments to ensure that clinicians are delivering care according to an intended service model. Although resources are often expended in fidelity measurement, associations between fidelity and client outcomes has not been well established in the psychotherapy literature. The relationship between clinician fidelity and treatment outcomes was investigated in a longitudinal sample of clinicians $(n=17)$ and parent-child dyads $(n=32)$ following a statewide implementation of Parent-Child Interaction Therapy. Observer-rated measures of adherence and coaching competence collected from early treatment sessions were used to predict intake levels and growth trajectories of parent-reported behavior problems and positive parenting skills. Hierarchical linear modeling results indicated that higher levels of coaching competence were associated with greater behavior problem frequency at intake. Neither early session adherence nor early session competence, as they were measured in the current study, predicted changes in treatment outcomes over time. These results suggest that additional variables should be modeled alongside early treatment fidelity to predict treatment outcome change. Possible explanations for these findings, limitations of the current study, and directions for future research are discussed. 


\section{Acknowledgements}

I would like to thank Dr. Amy Herschell for helping me develop a challenging project that I am interested in, and for allowing me to use data from her grant, RO1 MH09750: $A$ Statewide Trial to Compare Three Training Models for Implementing an EBT. I would also like to thank the other members of my committee, Dr. Aaron Metzger and Dr. Claire St. Peter, for their valuable feedback during the preparation and implementation of this study. I am also very grateful for all of the assistance I received from the members of the PCIT Across PA team at the University of Pittsburgh School of Medicine, especially Jon Hart and Kristen Schaffer. Finally, I would like to thank my wonderful husband, family, and friends for their kind acts of support and encouragement. 


\section{Table of Contents}

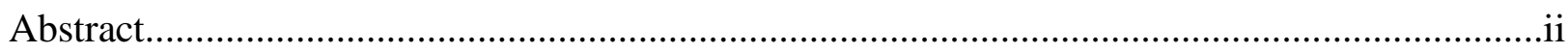

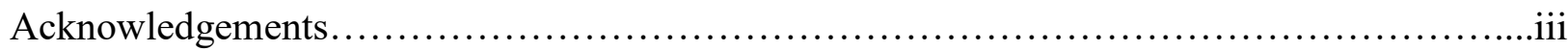

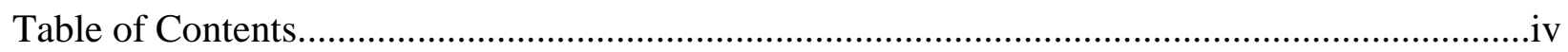

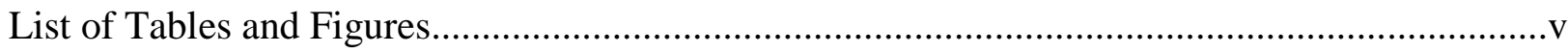

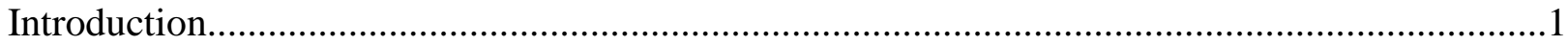

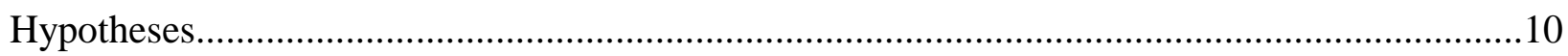

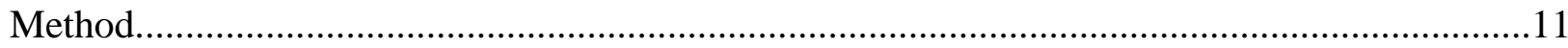

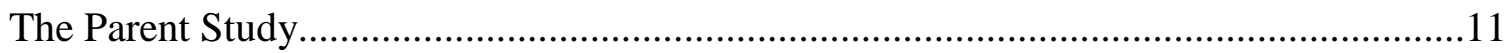

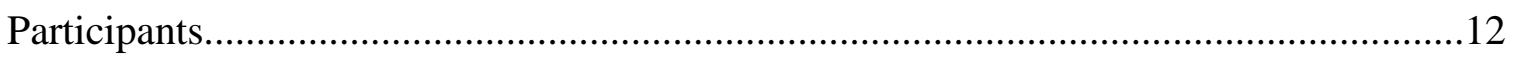

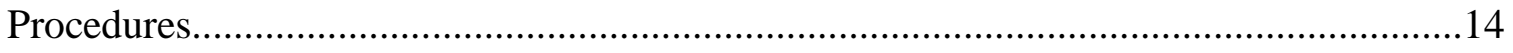

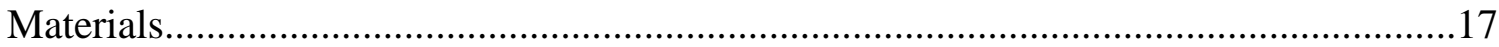

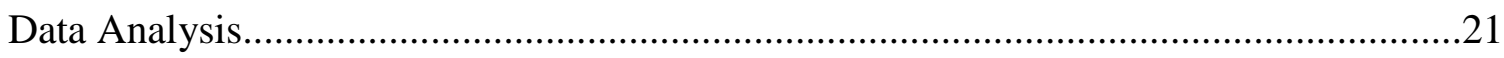

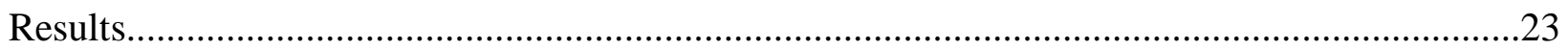

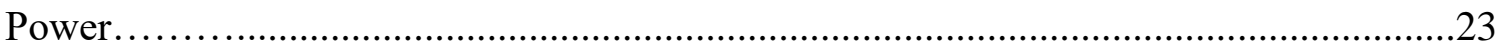

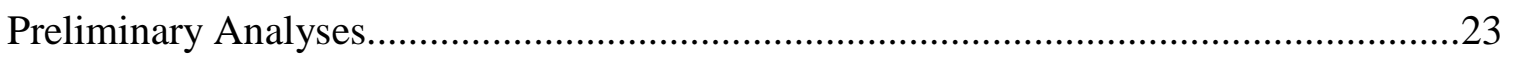

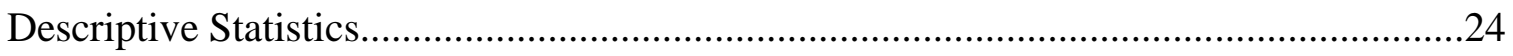

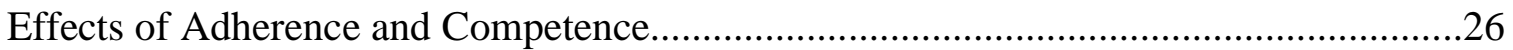

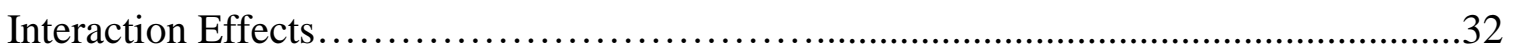

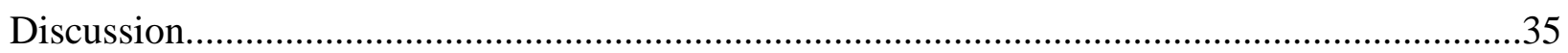

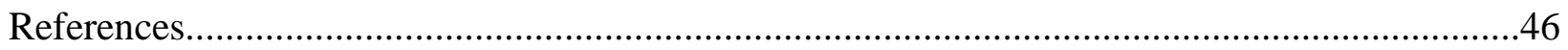

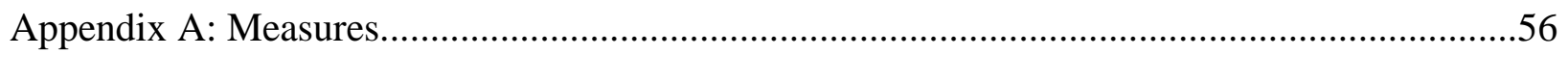

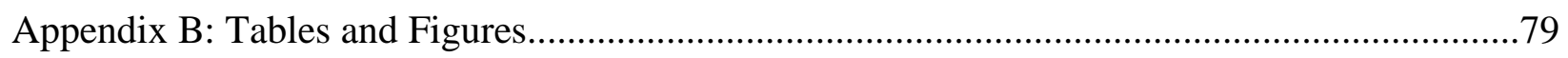




\section{List of Tables and Figures}

Figure 1: Flow of Video Selection for Participant Inclusion...............................................79

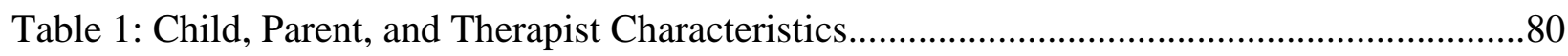

Table 2: Descriptive Statistics and Correlations among Variables..........................................81

Table 3: Fixed and Random Effects for Three-Level Models of Fidelity Predictors...................82

Table 4: Fixed and Random Effects for Three-Level Models of Adherence-Competence

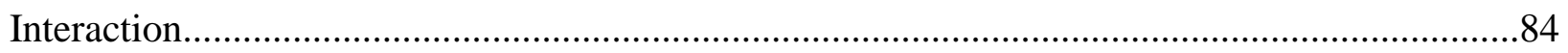

Figure 2: Change in Behavior Problem Intensity over Time................................................86

Figure 3: Change in Behavior Problem Frequency over Time.............................................87

Figure 4: Change in Positive Parenting over Time................................................................8 


\section{Introduction}

\section{Science-Practice Gaps in Community Behavioral Health}

Disruptive Behavior Disorders (DBDs) pose a considerable threat to the wellbeing of children, adolescents, and families in the United States. The National Survey of Children's Health has estimated that approximately 2.8 million children ages 3 to 17 years are diagnosed with Oppositional Defiant Disorder or Conduct Disorder (Perou et al., 2013). This data is concerning given the negative health outcomes that are associated with DBD diagnoses. Young children who exhibit disruptive behaviors are more likely to have worse academic outcomes and develop behavioral health problems in early adulthood (Capsi et al., 1996; Vitaro, Brendgen, Larose, \& Trembaly, 2005) compared to their same-aged peers. Children in this population are also at risk for both violent and nonviolent delinquency in adolescence (Trembaly et al., 1992; Tremblay, Pihil, Vitaro, \& Dobkin, 1994; Broidy et al., 2003). Early intervention has been associated with increased school attendance and decreased criminal and antisocial behaviors among children with DBDs (Boisjoli et al., 2007). Although a number of efficacious interventions are available for treating children with DBDs (Kaminski \& Claussen, 2017; Kazdin, 2018), they are not consistently accessible in community settings where families are likely to seek services (Weisz, Donenburg, Han, \& Weiss, 1995; Hoagwood et al., 2001).

Efforts to improve the utilization of evidence-based treatments in community behavioral and mental health centers have gained momentum in recent decades in response to increased recognition of this science-to-practice gap by national commissions and research agencies (Hoagwood \& Olin, 2002; President's New Freedom Commission on Mental Health, 2003). Interest in this area has resulted in the emergence of implementation science, a developing field of research which investigates processes underlying the uptake of evidence-based treatments by 
community-based clinicians (Rubenstein \& Pugh, 2006) Oftentimes, this research features indicators (e.g., fidelity, sustainability) that the implementation of a new practice is either successful or has the capacity to be successful (Proctor et al., 2009).

\section{Treatment Fidelity}

One of the most important constructs that is assessed in implementation research is treatment fidelity, also known as treatment integrity. Implementation frameworks describe treatment fidelity as the degree to which an intervention is delivered to clients as intended by the developer of that intervention (Nezu \& Nezu, 2008; Proctor et al., 2011). The components of treatment fidelity include adherence (i.e., the extent to which each of the required elements of the intervention are delivered), competence (i.e., the quality with which those elements are delivered), and in some cases, differentiation of the intervention from similar interventions (Waltz, Addis, Koerner, \& Jacobson, 1993; Perepletchikova, Treat, \& Kazdin 2007; Nezu \& Nezu, 2008). Most often, implementation research has focused on the first two of these components. These studies are interested in demonstrating that clinicians are using the recommended components of a treatment as often as prescribed in their practice (adherence) with sufficient skill (competence), so that the components are likely to have their intended effect. Adherent performance of a treatment would involve a clinician who completes all of the recommended tasks and activities that are suggested by a trainer or a manual. Competent performance of a treatment would involve a clinician correctly judging when treatment activities need to be used, using those activities for an appropriate duration of time, and using the treatment activities correctly (Perepletchikova \& Kazdin, 2005; Barber et al., 2007).

Although fidelity measures originated as tools for controlling intervention exposure in treatment efficacy studies, they have since been adopted as indicators of implementation success, representing the extent to which an intervention is used as prescribed by after some training or 
other implementation initiative has occurred (Breitenstein et al., 2010b; Schoenwald, 2011; Regan, Daleiden, \& Chorpita, 2013). Some relation between the successful implementation of an evidence-based treatment by clinicians (i.e., fidelity) and treatment success for individual clients is logically expected; and yet, it is important to note that implementation scientists view these events as being conceptually distinct. For example, the frequent use of therapeutic components that are recommended by an evidence-based treatment in one's practice (i.e., high adherence) does not necessitate any particular level of skill when delivering the technique (i.e., variable competence), which could lead to suboptimal treatment outcomes (Proctor et al., 2011). Thus, examination of adherence and competence alongside the measurement of patient outcomes is a common method in implementation research (Curran et al., 2012).

\section{Challenges in Fidelity Assessment}

Routine assessment of fidelity, or fidelity monitoring, has been encouraged as a critical step in psychotherapy trainings (Aarons, Hurlburt, \& Horwitz, 2011). The rationale for carefully monitoring fidelity during an implementation is both scientific and practical. Fidelity measures can improve the internal validity of a study by ensuring that all clients are receiving the independent variable (e.g., an intervention of interest) in similar dosages (Perepletchikova \& Kazdin, 2005). By extension, indices of fidelity allow researchers to make stronger inferences from their data, such as determining whether client outcomes are attributable to the intervention and implementation strategies employed (Schoenwald et al., 2011). Regular fidelity checks can also be leveraged clinically to improve the quality of treatment delivery in service systems.

A recurrent issue in the literature is that there is little consensus regarding how fidelity should be defined and measured. Fidelity is an inherently malleable construct; to the extent that discrete interventions consist of unique therapeutic components, those interventions will have unique criteria for determining whether adherence and competence are present. Because of this, 
the format of fidelity measures can vary widely across treatments, and fidelity values that are collected using one instrument may not necessarily be strongly correlated with measures collected using another (Schoenwald et al., 2011). There is additional inconsistency in how researchers conceptualize the components of fidelity, with some arguing that fidelity is strictly a construct of adherence, distinct from treatment quality or competence (Kendall \& Beidas, 2007). When interventions lack a clear protocol to guide fidelity assessment, or when multiple interventions are used by clinicians who operate within the same agency, confusion can quickly arise over which components are the most essential to evaluate (Herschell, 2010). To address these barriers, a clear delineation of core components for each treatment is needed and measures that map onto these components are needed to assess fidelity in a meaningful way.

\section{Does Fidelity Predict Treatment Outcome?}

Given the immense effort and resources that are expended during treatment implementations, it is important that stakeholders are equipped with evidence demonstrating that all treatment components enforced in fidelity monitoring are necessary for client behavioral change. It has been posited that fidelity to treatment protocols in their entirety is necessary for achieving optimal treatment outcomes (Mihalic, 2004; Forgatch, Patterson, \& DeGarmo, 2005). However, it has also been claimed that too much emphasis on treatment fidelity can compromise the long-term generalizability and sustainment of evidence-based treatments (Chambers, Glasgow \& Stange, 2013). The extant literature does not fully resolve this debate. Although increases in treatment fidelity do not consistently correspond with improvements in client outcome across all treatment modalities (Webb, DeRubeis, \& Barber, 2010; Eiraldi et al., 2018), treatment fidelity has been associated with several factors that are related to client outcome, such as clinician attitudes, clinician motivation, and client problem severity (Perepletchikova \& Kazdin, 2005). Other research has shown that moderate levels of treatment adherence are more 
predictive of treatment outcome than high levels of treatment adherence, suggesting a curvilinear fidelity-outcome relation (Barber et al., 2006). Moreover, it has not been demonstrated that adherence and competence, the two primary components of fidelity, are strongly correlated with one another (Miller \& Binder, 2002). The lack of a strong observed relationship between each element of fidelity may indicate that adherence and competence each relate to treatment outcome differently.

Discrepancies in the behavioral health literature make it difficult to predict what fidelityoutcome relations may look like for interventions that have not explored mechanisms of action in depth. In the child and family behavioral health literature, mechanisms of change underlying many evidence-based treatments are not well understood (Kazdin \& Nock, 2003). Thus, deviation from fidelity guidelines can be risky and compromise client health outcomes. "Flexibility within fidelity" has been suggested as a potential solution to the fidelity-outcome controversy, by encouraging individualization of treatments while maintaining adherence to major treatment components (Kendall \& Beidas, 2007). Although a compromise between strict fidelity and adaptation is potentially a more pragmatic approach to the dissemination of evidence-based treatments in community practice (McHugh, Murray, \& Barlow, 2009), further empirical exploration of the relation between fidelity and treatment outcome is warranted to build better theory and inform how this "flexibility" should be applied in the real world.

\section{Parent-Child Interaction Therapy}

Parent-Child Interaction Therapy (PCIT; Eyberg \& Funderburk, 2011) is a manualized behavioral parenting training intervention developed to treat DBDs in children 2-7 years of age. Efficacy research has demonstrated that PCIT can reduce child externalizing behaviors, mend parent-child relationships, increase child pro-social behaviors, and improve mental health outcomes of caregivers (Ward, Theule, \& Cheung, 2016). Additionally, implementation trials in 
community settings have demonstrated that PCIT can reduce problematic child behaviors and increase positive parenting practices in community practice (Lyon \& Budd, 2010; Budd et al., 2011). The PCIT treatment protocol consists of two discrete modules or treatment phases. The first phase is Child-Directed Interaction (CDI), which is designed to strengthen the caregiverchild relationship and decrease child noncompliance by increasing caregiver attention toward positive child behaviors and reducing caregiver attention towards negative child behaviors. The second phase of PCIT is Parent-Directed Interaction (PDI), which is designed to support caregivers as they learn to set consistent limits with the child that increase compliance following the delivery of clearly stated direct commands. The CDI and PDI modules are conducted using a in vivo coaching, allowing parents to practice new skills while receiving supportive feedback on the application of those skills from the clinician in real time. The PDI module provides parents with additional opportunities to practice generalizing their parenting skills outside of the therapy room and into other problem settings (e.g. in public settings, at school, with other relatives).

Evidence has supported the adaptation of PCIT to meet the needs of families with additional presenting diagnoses (e.g., Autism Spectrum Disorder, Separation Anxiety Disorder, Attention Deficit Hyperactive Disorder) and families with diverse cultural backgrounds (Matos, Bauermeister, \& Bernal, 2009; Lesack, Bearss, Celano, \& Sharp, 2014; Carpenter et al., 2014; Chronis-Tuscano et al., 2016). PCIT has also been adapted to novel delivery methods (e.g., home-based, group-based, and internet-based) to increase its accessibility (Galanter et al., 2012; Niec, Barnett, Prewett, \& Shanley, 2016; Comer et al., 2017). Even though multiple adaptations of the treatment exist, the importance of fidelity and consistency in treatment delivery is still emphasized (Ward, Theule, \& Cheung, 2016). To this effect, the PCIT manual contains a series of Treatment Integrity Checklists designed to assess treatment fidelity within individual sessions at the different stages of treatment (Eyberg \& Funderburk, 2011). 


\section{Treatment Adherence in PCIT}

Treatment adherence is the most frequently measured component of fidelity, to the extent that adherence and fidelity are commonly treated by researchers as interchangeable constructs. In the PCIT literature, treatment fidelity tends to be conceptualized as treatment adherence, rather than a combination of adherence and clinician competence. The Treatment Integrity Checklist in the PCIT treatment manual is the most commonly used fidelity tool for PCIT (Eyberg \& Funderburk, 2011). The items on this checklist, measured dichotomously, determine whether a clinician has completed specific therapeutic tasks included in the treatment manual for the recommended duration of time. The items on this checklist do not address the provider's skill level in completing the tasks, or the quality of the therapeutic exposure that families receive. Thus, the Treatment Integrity Checklist is mostly reflective of PCIT adherence.

Treatment adherence is often assumed to be a prerequisite for significant improvement in client behavior in PCIT. However, it has not been demonstrated empirically that strict adherence to the PCIT manual is necessary to achieve lasting improvements in family outcomes (Travis \& Brestan-Knight, 2013). Information on the relation between treatment adherence and client outcome would be highly valuable to implementation researchers and clinicians who wish to advance the use of PCIT in community settings. Evidence that adherence is associated with gains in family outcomes could justify the allocation of resources toward innovative adherence monitoring strategies that overcome the many challenges associated with fidelity assessment. Alternately, a demonstration that adherence is not strongly related to gains in family outcomes could prompt stakeholders to reevaluate any implementation plans that expend valuable resources on adherence monitoring. Implementation scientists may also be prompted to redesign or reassess these measures to ensure that they include the most relevant predictors of treatment gain. 


\section{Clinician Competence in PCIT}

Competence is measured less frequently than adherence in PCIT; it is more difficult to assess reliably and traditionally relies on evaluations conducted by treatment experts. Not many measures of PCIT competence have been developed or evaluated for psychometric quality (Davis III \& Brestan-Knight, 2013), leaving a gap in knowledge regarding competence-outcome relations. Previous research suggests that competence, including knowledge of treatment content, appropriate structuring of sessions, proficient use of clinical skills, and proficient engagement with families, does contribute uniquely to client outcomes in parent management training (Forgatch et al., 2005). This is balanced by research that asserts that only a moderate relation between measures of competence and outcome exists across treatment modalities (Barber et al., 2007). Previous studies of PCIT have also indicated that a clinician's particular coaching style (e.g., directive, responsive) may impact parent outcomes obtained over the course of treatment (Barnett, Niec, \& Acevedo-Polakovich, 2014; Caron, Bernard, \& Dozier, 2016; Barnett et al., 2017). If coaching style is a true predictor of parent engagement and parenting behaviors, fidelity measures that only capture adherence, but not coaching quality, may have limited utility when guiding the implementation of PCIT.

Because clinician competency has not been thoroughly explored in PCIT and there is potential for clinician competence to influence the treatment process, it is important to better understand how clinician competencies relate to child treatment outcomes. It could be the case that clinician competence moderates the relation between adherence and outcome by influencing parent engagement in treatment, or it could be that irregularities in the measurement of competence have biased this association in the literature. Investigations of how specific types of therapeutic competencies (e.g., knowledge of components, building rapport, coaching ability) relate to outcomes could optimize the selection of implementation strategies and the 
development of PCIT trainings that emphasize the most relevant PCIT skills. Furthermore, an increased research focus on the competence-outcome relation could enable researchers to improve fidelity measures such that key therapy skills are represented. More investigations in this area may also prompt further examination of the interaction between adherence and competence, providing a rationale for more specialized training in core competencies.

\section{The Current Study}

Previous research has not sufficiently addressed the relationship between treatment adherence, clinician competence, and family treatment outcomes across various types of psychotherapy (Barber et al., 2006; Breitenstein et al., 2010b; Eiraldi et al., 2018). This is especially true in the PCIT literature. It is critical that implementation science continues to advance its understanding of treatment fidelity across contexts given its scientific relevance and clinically useful properties. Variation in the behavioral health literature concerning fidelityoutcome relations may be driven in part by poor distinctions between adherence and competence (Breitenstein et al., 2010b). Therefore, it is important that future research on treatment fidelity makes appropriate conceptual distinctions between these components. The current study investigated relations between community clinicians' fidelity to the PCIT treatment protocol, specifically the CDI coaching module, and parent-child treatment outcomes. The study was conducted in the context of a statewide PCIT training initiative designed to compare the impact of multiple implementation strategies in community outpatient behavioral health clinics.

The current study consisted of three aims. The first aim was to examine the relation between levels of individual clinician CDI coaching adherence and trajectories of change in client treatment outcomes (e.g. child problem behaviors intensity, child problem behavior frequency, and positive parenting) from intake to 12 months post-intake. The second aim was to examine the relation between levels individual clinician CDI coaching competence and 
trajectories of change in client treatment outcomes from intake to 12 months post-intake. The third aim was to determine whether CDI coaching competence moderates the relationship between adherence and client outcomes.

\section{Hypotheses}

\section{Question 1}

Does clinician CDI coaching adherence predict changes in child and family treatment outcomes over time, as evidenced by a reduction in child problem behaviors and an increase in positive parenting practices post-treatment?

It was hypothesized that clinician adherence to the PCIT manual, as evidenced by the Treatment Integrity Checklist, will predict greater improvements in child problem behaviors, problem behavior frequency, and positive parenting practices. This hypothesis is consistent with literature supporting a relationship between adherence and outcome in other treatment modalities (Barber et al., 2006; Hogue et al., 2008). Additionally, because the Treatment Integrity Checklist has been used in treatment efficacy and effectiveness research, it is expected that higher scores on this checklist will be associated with improvements in treatment outcomes.

\section{Question 2}

Does clinician CDI coaching competence predict changes in child and family treatment outcomes over time, as evidenced by a reduction in child problem behaviors and an increase in positive parenting practices post-treatment?

It was hypothesized that clinician coaching competence in CDI, as evidenced by the FIRST Coach Coding System, will predict improvements in child problem behaviors, problem behavior frequency, and positive parenting practices. This hypothesis is consistent with evidence supporting coaching skill as a potential predictor of treatment outcome in PCIT (Barnett, Niec, \& Acevedo-Polakovich, 2014; Caron, Bernard, \& Dozier, 2016; Barnett et al., 2017). 


\section{Question 3}

Does clinician coaching competence moderate the effect of treatment adherence on behavior problem intensity, behavior problem frequency, and positive parenting skills?

It was hypothesized that competence will moderate the effect of adherence on treatment outcome, given that adherence to certain treatment components (e.g., live parent coaching) is necessary in order to achieve higher levels of clinical competence.

\section{Methods}

\section{The Parent Study}

Archival data from an existing study funded by the National Institute of Mental Health (NIMH; R01 MH095750; A Statewide Trial to Compare Three Training Models for Implementing an Evidence Based Treatment; PI: Herschell) was used to conduct the proposed study. The parent study was designed to evaluate three distinct PCIT training models in outpatient behavioral health clinics across the state of Pennsylvania. The training models that were compared were the Cascade Model (i.e. "train-the-trainers" model), Learning Collaborative, and Distance Education (i.e. technology-based training). In the Cascade Model

condition, PCIT experts provided a training to professionals within an agency so that those same professionals could in turn provide training to other clinicians within the same agency. In the Learning Collaborative condition, stakeholders at multiple levels within an agency (e.g. clinicians, administrators, supervisors) met on a regular basis to enact implementation strategies and facilitate team-based collaboration between all professionals involved in the implementation. In the Distance Education condition, clinicians acquired PCIT knowledge and skill through selfdirected utilization of automated training materials (e.g. video tapes or online programs). The parent study aimed to evaluate changes in clinician knowledge and skill after training and compare client outcomes across each of the training approaches (Herschell et al., 2015). 


\section{Participants}

The participants of the current study included clinicians and parent-child dyads that were recruited as part of a statewide PCIT implementation initiative. Clinicians in the parent study were recruited from behavioral health outpatient clinics across the state of Pennsylvania to take part in PCIT trainings. Parent-child dyads were the recruited if they were entering treatment with clinicians who had received the PCIT training. A total of 100 clinicians and 228 parent-child dyads were recruited from these clinics to participate in the parent study. Participants for the current study were obtained through random sampling of therapy session videos that were submitted as part of the parent study data collection procedures. A description of the flow of participants from the parent study to the current study is provided in Figure 1. The current study included a final count of 17 clinicians and 32 parent-child dyads from the larger parent study. This sample of dyads was lower than the sample that was originally estimated by investigators ( $n$ $=43$ ) because investigators had incorrect estimates of the number of videos that represented the same parent-child dyads. At the time that families were enrolled in the study and clinicians were asked to submit videos, clinicians had not reached mastery for all training check-outs.

Research staff recruited clinics and clinicians to participate in the parent study. A total of 94 eligible clinics were identified from a pool of licensed outpatient mental health organizations that operated in only one county (to avoid contamination effects), served children the appropriate age for PCIT, had not participated in prior PCIT training, and agreed to attend an informational meeting. All eligible clinics were approached for participation, and 50 clinics in total agreed to take part in the parent study. The inclusion criteria for clinician participants included the following: current employment status at a clinic that was participating the in the PCIT training initiative, an active caseload consisting of clients appropriate for treatment with PCIT (i.e. children ages 2 to 7 years of age exhibiting disruptive behaviors), were willing to complete PCIT 
training, had not previously received training in PCIT, and were willing to complete research questionnaires and videotape therapy sessions for research purposes.

Clinician participants were responsible for the recruitment of parent-child dyad participants. After receiving PCIT training, each clinician participating in the study was asked to disseminate research recruitment information to families who were active on their caseload and would be receiving PCIT. Families who were interested in research participation provided contact information to the clinician, who then shared it with research staff via a "Permission to Contact" form. Blank "Permission to Contact" forms were also provided to research staff when families denied consent to track the total number of families approached for recruitment. Research staff followed up with parents who provided their contact information, obtained their informed consent, and communicated that parents could decline participation if desired. Parentchild dyads were excluded from participation in the study if the child being seen for treatment was a ward of the state or living under state custody, as Pennsylvania law mandates that these children are ineligible for research participation.

Demographics data were reported for clinicians and parent-child dyads who were represented in the current study. Characteristics of clinicians, parents, and children in the current study are reported in Table 1. Clinicians had a mean of 16.47 years of experience $(S D=10.49)$, and a mean of 1.55 years working at their agency $(S D=0.93$. Clinician degrees were held in social work (44\%), psychology (41\%), education (3\%), and other disciplines (12\%). Clinicians were representative of all training conditions conducted in the parent study: Cascade Model (44\%), Learning Collaborative (34\%), and Distance Learning (22\%). Clinicians in the study were exclusively White (100\%) and female (100\%). A majority of parents in the study were White (84\%), female (90\%), Non-Hispanic (90\%), employed full-time (55\%), were single (38\%), and had an annual income of less than $\$ 14,999$ (42\%). A majority of children in the study 
were White (84\%), male (75\%), Non-Hispanic (88\%), and had at least one behavioral health diagnosis at the time of participation $(67 \%)$.

\section{Procedures}

Videotaped recordings of PCIT sessions with consented parent-child dyads were collected by the clinician participants. Clinicians were encouraged to submit their videotaped therapy sessions to research staff after recording them via a secure online system or via mail using encrypted flash drives and DVDs. One video camera was sent to each participating clinic. Research staff set up each camera before sending it to a participating clinic, and research staff were available to clinicians throughout the duration of the study to provide technical support with video recording. In addition, instructional videos on how to properly use the video cameras were made available to participating clinicians. Multiple incentives were offered to clinicians for submitting video recordings of therapy sessions over the duration of the parent study. These incentives included a $\$ 30$ payment for the return of any video featuring a new family and $\$ 10$ payments for each additional video submitted of a previously recorded family. Reminders to submit videos were given to clinicians periodically during consultation sessions, and researchers would routinely provide feedback to clinicians identifying the number of videos that had been received.

A total of 360 session videos were submitted to the research team across all clinicians and training conditions (117 Cascade Model; 111 Learning Collaborative; 78 Distance Education), and 93 of the videos submitted reflected CDI coach sessions. Videos of CDI coach sessions were not considered for fidelity coding if they were collected prior to the second CDI coach session because treatment integrity checklist items differ between the first CDI coach session and subsequent CDI sessions. The rationale for excluding the first CDI coach session at this stage was that the denominator used to calculate the adherence percentage would differ 
across CDI sessions that were coded. Stratified random sampling was utilized to select 45 videos (15 per training condition) from the remaining pool of submitted CDI videos. A break-down of this procedure is included in Figure 1.

The final set of 45 sampled videos were coded for adherence and competence and were reviewed for inclusion in the current study. A total of 13 videos from the selected pool represented duplicate families for a total of 32 unique family videos. Since the current study was interested in examining family-level outcomes, duplicates could not be included and videos that represented duplicate families were removed using random selection. Coding of all PCIT session videos for adherence and competence occurred prior to the beginning of the current study.

The sampled videos were coded by two undergraduate students for treatment adherence using the Treatment Integrity Checklist, and 30\% of the videos were double-coded. Both students were trained to use the checklist by a PCIT coding expert. Interrater reliability estimates, calculated as the percentage of double-coded videos that represented the exact same adherence score, indicated approximately 50\% agreement between the coders for treatment adherence. Approximately 16 of the 32 videos included in the current study (50\%) were flagged by adherence coders as having either poor audio-video quality or parts of the video cut out during recording (i.e., started late or ending early).

After adherence coding was conducted, the same sample of videos were sent to an external team of coders to assess CDI coaching competence using the FIRST Coach Coding System. Primary coding was conducted by a competence coding expert who was also a developer of the FIRST Coach Coding System. Interrater reliability for FIRST Coach Coding ratings between the primary coder and reliability coder indicated approximately $95 \%$ agreement $($ Cohen's kappa $=.81)$ for coaching mastery, 95\% agreement for coaching statements (Cohen's kappa $=.89), 95 \%$ agreement for coaching errors $($ Cohen's kappa $=.73), 100 \%$ agreement for 
praise $($ Cohen's kappa $=1.00), 86 \%$ agreement for half of praise being labeled $($ Cohen's kappa $=$ .71 ), and 93\% agreement for meeting stylistic features (Cohen's kappa $=.85)$. During competence coding, three videos were removed from the dataset due upon discovering that the families had not completed video-recording consent forms. Three additional videos were randomly sampled to replace the three videos that did not have video-recording consent, and these three videos were coded by the adherence coding team. However, they were not coded for competence due to the late timing of the error.

Clinician participants completed assessments related to their professional practice and training experiences at baseline (before training), 6-month follow-up, 12-month follow-up, and 24-month follow-up. The 12-month time point represented the end of the active implementation period where clinicians were receiving support from trainers, and the 24-month point represented 1-year follow-up. In addition, clinicians completed discharge packets for each of the parent-child dyads that summarized details of the case such as session attendance, the reason that treatment of the case was being terminated, and the clinician's impression of how strongly their treatment of the case adhered to treatment integrity checkpoints outlined in the PCIT protocol. Incentives for therapist participants included free training in PCIT, Continuing Education credits for completing the training, and payment for assessment completion at each of the measurement time points. Specific incentives for completing assessments were awarded to clinicians as follows: \$25 received at baseline and 6-month follow-up, \$30 received at 12-month follow-up, and $\$ 40$ received at 24-month follow-up.

Parent participants were asked to complete assessments online (79\%), over the phone $(11 \%)$, or in the mail $(10 \%)$ depending on their preference at the time of recruitment. Administration of the parent assessment batteries occurred at four distinct time points: baseline (intake), 3-month follow-up, 6-month follow-up, and 12-month follow-up. The assessments in 
the parent battery included demographics information, child-focused assessments that captured intensity of child problem behaviors, parent measures of depression and anxiety, parenting practices, and assessments that captured treatment participation, perceived barriers to treatment and satisfaction with treatment. Incentives for parent participants included payment for each completed assessment battery. Specific incentives for completing assessments were awarded to parents as follows: $\$ 30$ received at baseline and 3-month follow-up, $\$ 30$ received at 6-month follow-up, and $\$ 40$ received at 12-month follow-up. Assessments were conducted with participating parents even after they had graduated or exited early from treatment.

\section{Materials}

\section{$\underline{\text { Video Recording Equipment }}$}

Video cameras for recording CDI and PDI therapy sessions were distributed to each participating clinic by the research team. Older camera models were chosen strategically by the research team to produce smaller electronic file sizes that could be shared more easily between clinicians and researcher personnel. Written instructions for operating cameras were also provided to each participating clinic along with the video recording equipment.

Measures for Coding Behavioral Observations of Fidelity

\section{Treatment Integrity Checklist for CDI}

Clinician fidelity to specific CDI session components was assessed using the Treatment Integrity Checklist from the Parent-Child Interaction Therapy Protocol (Eyberg \& Funderburk, 2011). The checklist, which outlines key components of the PCIT protocol and their projected duration, was utilized to indicate which treatment manual elements for CDI coach session were observed during video review of each randomly selected CDI coach session $(N=45)$.

Each component listed on the Treatment Integrity Checklist fell into three main categories: tasks that were completed by the clinician before the CDI session (preparation and 
check-in), tasks that were completed during the session, and tasks that were completed after the session (wrap-up). Items on the checklist that were relevant to the session being coded depended upon how many parents were present in the therapy session (with one parent, 9 items were coded; with two parents, 12 items were coded to reflect additional steps). Each component was measured dichotomously (either as present, or as not present). Items indicated on the checklist were summed and divided by the total number of items possible to generate a fidelity score in the form of a percentage. Higher percentages on the Treatment Integrity Checklist indicated stricter adherence to manualized treatment components.

FIRST Coach Coding System for CDI Coaching in PCIT (FCCS-CDI)

Clinician CDI coaching competence was measured using the FIRST Coach Coding System for CDI Coaching in PCIT (FCCS-CDI). The FCCS-CDI is an observational tool meant to be completed by a trained coder during a five-minute review of CDI coaching sessions. The FCCS-CDI was designed to provide feedback to PCIT trainees and improve parent coaching skill according to the PCIT International Training Guidelines. In order to achieve coaching "mastery" on the FCCS-CDI, clinicians had to meet five criteria: coaching pace (i.e., frequent use of coaching statements, coaching accuracy (i.e., labeling parent skills correctly and giving appropriate directions), positive tone (i.e., frequent use of praise statements), use of specific praises, and use stylistic features. Stylistic features included praising the parent for using more than core CDI skills, praising the spontaneous uses of CDI skills, praising use of CDI skills that were contingent upon clinician feedback, minimizing the use of "line feeding" to parents, describing features of the parents or child during play, avoiding feedback on negative parenting skills, and linking parent behaviors to the purpose of CDI.

Each mastery criterion was assessed by tallying the occurrence of a specific clinician behaviors and determining whether individual cutoffs for the criterion had been reached within 
the five-minute coding period. Adequate pacing was satisfied by giving 35 or more coaching statements. Adequate accuracy was satisfied by making fewer than 3 coaching errors (e.g., making inappropriate suggestions to parents, making irrelevant remarks, incorrectly labeling CDI skills). Adequate positive tone was satisfied by giving 10 or more praises to the parent. Adequate specific praise was satisfied by ensuring that at least half of praises were labeled as opposed to unlabeled (e.g., "Great job" would be an unlabeled praise, while "Great job following along with your child's play" would be a labeled praise). Stylistic features were satisfied if 4 out of 7 features were present. Overall clinician mastery of coaching was indicated (yes or no) if all 5 mastery criteria were met. In the current study, clinician competence was measured by scoring the percentage of mastery criteria that were met on the FCCS-CDI.

\section{Measures Completed by Clinicians:}

\section{Clinician Background and Contact Information Form}

Demographic variables such as race/ethnicity, gender, age, and professional characteristics for clinicians were collected using the Clinician Background and Contact Information Form. This form was administered to clinicians at baseline, prior to the training phase and prior to parent-child dyad recruitment.

\section{Treatment Summary Report (TSR)}

The nature and outcome of treatment services that were provided, including information regarding early discharge or termination from PCIT, was captured in the Treatment Summary Report. The TSR was completed by clinicians to report therapeutic activities that took place up to the time of discharge for a specific case. The TSR contains 22 multiple choice and open response items. For the purposes of the proposed study, the TSR was used to identify parentchild dyads who were terminated from treatment before reaching graduation and assess the number of sessions that each parent-child dyad received. 
Measures Completed by Parents:

Demographics Information Form (Family)

Demographic variables such as race, ethnicity, gender, age, parent marital status, household income, education level, and number of children living in the household were collected from participating parent-child dyads using the Demographic Information Form (Family).

Eyberg Child Behavior Inventory (ECBI)

The Eyberg Child Behavior Inventory (ECBI; Eyberg \& Pincus, 1999) was used to measure the intensity of specific problem behaviors in children that were treated as part of the parent-child dyads. The ECBI is appropriate for use with children ages 2 to 16 , and it contains 36 items that assess both how regularly a behavior problem occurs (contributing to the intensity scale) as well as the degree to which the behaviors are a problem for the parent (contributing to the problem scale). Each item lists the problem behavior, and parents rate the intensity with which the behavior occurs on a 7-point Likert scale and circles "Yes" or "No" to indicate whether the behavior they rated is a problem for them. Larger scores on the intensity and problem scales indicate higher frequencies of parent-observed disruptive behaviors and more problematic parental attitudes towards those behaviors. Psychometrics for the ECBI are strong, with both scales yielding satisfactory test-retest reliability at 12 weeks (intensity $=.80$; problem $=.85$ ) (Funderburk et al., 2003). Inter-rater reliability has also demonstrated positive correlations for the intensity $(r=.86)$ and problem $(r=.79)$ scales (Eyberg \& Pincus, 1999). Concurrent validity for the ECBI has also been demonstrated with internalizing and externalizing subscales of Child Behavior Checklist (Achenbach, 1994), with coefficients of $r=.75$ and $r=.67$, respectively (Boggs, Eyberg, \& Reynolds, 1990). The ECBI intensity scale was used in the 
current study as a primary outcome to assess changes in child problem behaviors before, during, and after PCIT.

Alabama Parenting Questionnaire, Short Form (APQ-9)

The Alabama Parenting Questionnaire, Short Form (APQ-9; Elgar, Waschbusch, Dadds, \& Sigvaldason, 2007) assesses parenting practices of caregivers in the participating parent-child dyads. The APQ-9 is an abbreviated version of the original Alabama Parenting Questionnaire (APQ; Frick, 1991) for assessing parenting behaviors which contains nine items divided into three subscales: positive parenting practices, inconsistent discipline, and poor supervision. Items on the APQ-9 are written on a 5-point Likert-type scale indicating the intensity with which different parenting behaviors occur $(1=$ Never, 5 = Always $)$. Items from each subscale were summed to form a total positive parenting score, inconsistent discipline score, and poor supervision score. Moderate internal consistency for the APQ-9 subscales has been demonstrated with Cronbach's Alpha values ranging from .57 to .61. Criterion validity for the subscales was supported by a moderate correlation with child symptom scores in a range of coefficients from .64 to .90 (Elgar et al., 2007). The APQ-9 was used in the current study as a primary outcome to assess parenting practices over the course of treatment.

\section{Data Analysis}

Given that the data in the current study had a nested structure, a hierarchical analytic approach was necessary to assess the independent effects of clinician-level fidelity on parentchild outcomes. Three separate three-level growth models were estimated using hierarchical linear modeling (HLM; Bryk \& Raudenbush, 1992) to examine the effects of clinician treatment adherence and clinician coaching competence on behavior problem intensity (i.e., the ECBI Intensity scale), behavior problem frequency (i.e., the ECBI Problem scale), and positive parenting practices (i.e., the APQ-9 Short Form Positive Parenting scale). Level 1 of each model 
estimated growth trajectories, or changes, in parent-child dyads' outcome scores over time after their intake appointment. Level 2 of each model estimated the variations in the intercepts (i.e., intake values) and trajectories of treatment outcome scores within individual clinicians. Level 3 of each model estimated variations in the intercept and trajectories of outcome scores across clinicians. Models were estimated with HLM software, Version 7.3, and full maximum likelihood estimation was used to estimate missing values in the analyses. Each model estimated both fixed and random effects at the parent-child and clinician levels to assess remaining variability in treatment outcomes that was unaccounted for by the included predictors.

One additional treatment outcome (parental attitudes toward treatment) and a timevarying covariate (parent-perceived barriers to treatment participation) were originally included in the hypothesized models. However, further exploration of the archival data from the parent study revealed that these variables were not actually gathered at all four assessment points and would introduce a substantial amount of missing data to the models if included, hindering the ability to arrive at stable estimates. Thus, these variables were excluded from the analyses.

Early attrition of parent-child dyads from treatment was also included as a potential covariate in the hypothesized model. Attrition was expected to account for differences in the relationship between fidelity and treatment outcomes across families, as a lack of training in the second phase of treatment (PDI) would be expected to affect treatment gains regardless of clinician behaviors in the first phase of treatment. Rather than assess attrition dichotomously, the number of PDI sessions attended was introduced at Level 2 of each model to control for potential effects of PDI session dosage on treatment outcomes. To determine whether the inclusion of number of PDI sessions attended in the models improved model fit, each model was estimated with and without the number of PDI sessions, and the deviance statistics (i.e., estimates of fit between the proposed models and the observed data) were compared using chi-square tests. 


\section{Results}

\section{Power of Analyses}

Repeated measure observations fit more easily to multilevel models when there is an adequate sample size and at least three assessment points or repeated measures collected for each individual unit of analysis (Curran, Obeidat, \& Losardo, 2010). Since four assessment points were used in the parent study, the requirement for number of repeated measures was satisfied. The literature on multilevel modeling recommended that samples of at least 20 were used at the highest level of analysis (Tabachnick \& Fidell, 2014). The clinician sample size in the current study was 17 , falling slightly below this recommendation. Thus, the results of the current study were expected to be slightly under-powered to detect true effects in the data.

\section{Preliminary Analyses}

Preliminary analyses and descriptive statistics were performed using IBM SPSS Statistics software, Version 24.

Missing Data. Missing value analysis indicated $29.70 \%$ missingness on the ECBI Intensity scale (behavior problem intensity), 36.70\% missingness on the ECBI Problem scale (behavior problem frequency), and $28.10 \%$ missingness on the APQ-9 Positive Parenting scale. Little's MCAR test was not significant, $X^{2}(1014, N=128)=601.85, p=1.000$, indicating that data in the sample was missing completely at random. Further examination of Little's MCAR test at the 12-month point was also non-significant, $X^{2}(396, N=32)=206.25, p=1.000$, indicating that missing data was not likely associated with family attrition.

Assumption Checks. Analyses were conducted to examine the normality of residuals, outliers, and homogeneity of variance. Normality was assessed using estimates of residual skew and kurtosis, as well as visual inspection of P-P plots. The APQ-9 positive parenting scale was slightly negatively skewed (skew $=-1.06, S D=.26$ ). To address this violation, the scale was 
reverse-scored and square-root transformed. No other measures were problematically skewed or kurtotic following this transformation. Measures of behavior problem intensity and behavior problem frequency were not problematically skewed or kurtotic. Cook's distance and Mahalanobis's distance did not indicate bivariate or multivariate outliers. Homogeneity of variance across time was assessed using Levene's test for equality of variance. Levene's test was not significant for the ECBI Intensity scale, $F(3,86)=0.34, p=.793$, the ECBI Problem scale, $F(3,77)=0.89, p=.450$, or the APQ-9 Positive Parenting scale, $F(3,88)=0.85, p=.470$, indicating that error variance did not change significantly across the assessment points.

\section{Descriptive Statistics}

The means, standard deviations, and ranges of variables at each time point, as well as the correlations between variables, are provided in Table 2. Clinicians in the current sample displayed moderate levels of CDI coaching competence $(M=0.56, S D=0.32)$ and higher levels of CDI session adherence $(M=0.70, S D=0.25)$. Parents reported clinically significant behavior problem intensity at intake $(M=162.31, S D=39.72)$ and 3 -months follow-up $(M=134.84, S D=$ 50.78), and problem intensity declined across families over time. Clinically significant behavior problem frequency was reported at intake $(M=22.57, S D=8.90), 3$-month $(M=19.00, S D=$ 11.10), and 6-month follow up $(M=15.00, S D=11.04)$. Average problem frequency also declined over time across families. Positive parenting skills did increase slightly from intake ( $M$ $=12.93, S D=2.13)$ to 12 -month follow-up $(M=13.64, S D=1.47)$; however, these scores did not increase consistently across families at all time points. Correlations indicated that CDI coaching competence was not significantly associated with CDI session adherence $(r(112)=.13$, $p=.163)$. There was a strong significant association between the two ECBI subscales $(r(80)=$ $.79 p<.001)$. There were also significant correlations between CDI coaching competence and 
behavior problem intensity, $r(81)=.29 p=.008$, behavior problem frequency, $r(72)=.38 p=$ .001 , and positive parenting skills, $r(83)=.22, p=.042$.

Parent-child dyads in the current sample were representative of all three training conditions from the parent study. A total of 11 dyads (34\%) were treated by clinicians in the learning collaborative condition, 14 dyads (44\%) by clinicians in the cascade model condition, and 7 dyads $(22 \%)$ by clinicians in the distance learning condition. Most of the outcome assessments returned by parents were conducted online $(n=66 ; 52 \%)$. An additional 22 assessments were completed on paper (17\%), 8 assessments were completed over the phone (6\%), and 32 assessments were not completed (25\%). The Treatment Summary Report indicated that in the current sample 29 dyads (90.63\%) completed CDI training, 14 dyads $(43.75 \%)$ completed PDI training, and 11 dyads (34.38\%) graduated from treatment.

Chi-Square tests of association were conducted to ensure that outcome variables did not differ significantly across gender groups, training conditions, assessment methods, and phases of PCIT completed. The ECBI Intensity scale did not differ across levels of child gender, $X^{2}(78, N$ $=90)=74.59, p=.589$, parent gender, $X^{2}(78, N=90)=70.94, p=.702$, clinician training condition, $X^{2}(156, N=90)=161.27, p=.370$, assessment method, $X^{2}(156, N=90)=140.12, p=$ .814 , CDI completion $X^{2}(78, N=90)=61.41, p=.916$, or PDI completion, $X^{2}(78, N=90)=$ $77.70, p=.488$. The ECBI Problem scale did not differ across levels of child gender, $X^{2}(31, N=$ $81)=21.53, p=.897$, clinician training condition, $X^{2}(62, N=81)=66.49, p=.325$, assessment method, $X^{2}(62, N=81)=44.88, p=.950$, CDI completion $X^{2}(31, N=81)=31.19, p=.457$, or PDI completion, $X^{2}(31, N=81)=34.35, p=.310$. The Problem scale did differ significantly across levels of parent gender, $X^{2}(31, N=81)=47.04, p=.032$; however, this may be partially explained by the large difference in cell size between male parents $(n=3)$ and female parents $(n$ =29) included in the current sample. The APQ-9 Positive Parenting scale did not differ across 
levels of child gender, $X^{2}(7, N=92)=7.03, p=.426$, parent gender, $X^{2}(7, N=92)=5.52, p=$ .597 , clinician training condition, $X^{2}(14, N=92)=18.08, p=.203$, assessment method, $X^{2}(14, N$ $=92)=21.41, p=.092$, or CDI completion $X^{2}(7, N=92)=5.24, p=.631$. The Positive Parenting scale did differ across levels of PDI completion, $X^{2}(7, N=92)=17.06, p=.017$.

Parent Study Comparisons. Independent samples t-tests were conducted to determine whether outcomes distributions for families in the current sample were different from those observed in parent study families who were not in the current sample. Current participants $(M=$ $162.31, S D=39.72)$ did not differ significantly from parent study participants $(M=154.99, S D=$ $40.00)$ on the ECBI Intensity scale, $t(186)=.91, p=.366$. Current participants $(M=22.57, S D=$ 8.91) also did not differ from parent study participants $(M=22.09, S D=6.94)$ on the ECBI Problem scale, $t(167)=.32, p=.751$. Similarly, there was no significant difference between current participants $(M=12.93, S D=2.13)$ and parent study participants $(M=13.53, S D=1.80)$ on the APQ-9 Positive Parenting scale, $t(189)=-1.61, p=.109$.

An independent samples t-test was also conducted to determine whether clinicians in the current study different from clinicians in the parent study in terms of years of experience and number of years working at their agency. Clinicians from the current study $(M=16.47, S D=$ 10.49) did not differ significantly from non-study clinicians $(M=11.42, S D=8.20)$ in years of experience, $t(98)=1.97, p=.052$. Clinicians from the current study $(M=1.55, S D=0.93)$ also did not differ from non-study clinicians $(M=4.82, S D=5.61)$ in number of years working at their agency, $t(98)=0.05, p=.960$.

\section{Effects of Adherence and Competence}

Multilevel models were created in a series of steps, with unconditional models created first (i.e., models with no predictors, including time), intercepts and slopes models created second (i.e., models with time added as a predictor), and conditional models created last (i.e., the 
full models with predictors and covariates added). Intraclass correlation coefficients (ICC's) were calculated to determine the proportion of variance explained by nesting in the data and to confirm whether multilevel analyses were appropriate. Comparisons of deviance statistics were conducted during model building to determine whether each consecutive step improved the fit of the models to the observed data and whether the addition of the number PDI sessions completed by parent-child dyads improved model fit. Results from each step are organized by treatment outcome. Fixed effects and random effects from all conditional models are reported in Table 3.

Effects on Behavior Problem Intensity. The unconditional model indicated the that behavior problem intensity differed across groups in the sample, Coefficient $=138.18, t(12)=$ $14.31, p<.001$. Intercept variance at level 3 was significant, Coefficient $=476.04, X^{2}(12, N=$ 13) $=21.34, p=.045$, suggesting that behavior problem intensity differed across clinicians.

Level 2 intercept variance was also significant, Coefficient $=928.12, X^{2}(13, N=26)=40.39, p<$ .001 , suggesting that behavior problem intensity differed even more within clinicians, or across parent-child dyads. These variances indicated that additional predictors were needed to account for differences between groups. ICC estimates indicated that approximately $48 \%$ of the variation in behavior problem intensity was attributed to within-dyad differences, $34 \%$ was attributed to differences across parent-child dyads, and $17 \%$ was attributed to differences across clinicians. Thus, a multilevel model was considered appropriate.

Intercepts and Slopes Model. Deviance comparisons indicated that the intercepts and slopes model provided a significantly better model fit compared to the unconditional model, $X^{2}$ $(5, N=108)=37.14, p<.001$. The intercepts and slopes model indicated that without accounting for additional predictors, behavior problem intensity scores tended to decrease each month following intake, Coefficient $=-4.58, t(12)=-6.45, p<.001$. Level 3 intercept variance was significant, Coefficient $=670.58, X^{2}(12, N=13)=28.64, p=.005$, and level 3 slope 
variance was not significant, Coefficient $=0.49, X^{2}(12, N=13)=12.39, p=.415$, suggesting that behavior problem intensity varied across clinicians at intake; however, the rate of problem intensity change did not vary across clinicians when accounting for time. Both significant intercept variance, Coefficient $=663.67, X^{2}(8, N=21)=23.33, p=.003$, and slope variance, Coefficient $=0.78, X^{2}(8, N=21)=19.51, p=.005$, were observed at level 2 , suggesting that behavior problem intensity at intake and the change in behavior problem intensity varied across parent-child dyads when accounting for time.

Conditional Model. Deviance comparisons indicated that the conditional model did not significantly improve model fit compared to the intercepts and slopes model, $X^{2}(4, N=108)=$ $8.13, p=.086$. However, the conditional model did improve model fit compared to the unconditional model, $X^{2}(9, N=108)=45.26, p<.001$. The addition of number of PDI sessions as a covariate did not significantly improve the fit of the conditional model, $X^{2}(13, N=108)=$ $11.47, p>.500$. Thus, the number of PDI sessions were not retained in the conditional model. The conditional model indicated that neither coaching competence, Coefficient $=45.52, t(10)=$ $1.36, p=.205$, nor treatment adherence, Coefficient $=25.66, t(10)=0.60, p=.562$, predicted behavior problem intensity at intake. Neither coaching competence, Coefficient $=-3.97, t(10)=-$ $1.56 p=.150$, nor treatment adherence, Coefficient $=6.70, t(10)=2.04, p=.069$, predicted change in behavior problem intensity over time.

Level 3 intercept variance was significant, Coefficient $=340.04, X^{2}(10, N=108)=20.19$, $p=.027$, and level 3 slope variance was not significant, Coefficient $=0.15, X^{2}(10, N=108)=$ $10.16, p=.427$. This indicated that there was unexplained variance across clinicians in behavior problem intensity at intake, but not in intensity change over time, when accounting for treatment fidelity. Both significant intercept variance, Coefficient $=821.87, X^{2}(8, N=108)=24.51, p=$ .002 , and slope variance, Coefficient $=0.01, X^{2}(8, N=108)=20.68, p=.008$, were observed at 
level 2. This indicated that there was more variance across parent-child dyads than across clinicians in behavior problem intensity at intake and in behavior problem intensity over time when accounting for treatment fidelity.

Effects on Behavior Problem Frequency. The unconditional model indicated that there were differences in the level of behavior problem frequency across groups in the sample, Coefficient $=18.83, t(12)=9.14, p<.001$. Level 3 intercept variance was significant, Coefficient $=22.59, X^{2}(12, N=13)=22.01, p=.037$, suggesting that behavior problem frequency differed across clinicians. Level 2 intercept variance was also significant, Coefficient $=35.70, X^{2}(12, N=25)=30.99, p=.002$, suggesting that parent-child dyads differed in behavior problem frequency. ICC estimates indicated that approximately $51 \%$ of the variation in behavior problem frequency was attributed to within-dyad differences, $30 \%$ was attributed to differences across parent-child dyads, and $19 \%$ was attributed to differences across clinicians. A multilevel model was considered to be appropriate.

Intercepts and Slopes Model. Deviance comparisons indicated that the intercepts and slopes model provided a significantly better model fit compared to the unconditional model, $X^{2}$ $(5, N=108)=24.26, p<.001$. The intercepts and slopes model indicated that without accounting for other predictors, behavior problem frequency tended to decrease each month following intake, Coefficient $=-1.03, t(12)=-4.44, p<.001$. Level 3 intercept variance was not significant, Coefficient $=20.09, X^{2}(12, N=13)=19.51, p>.076$, and level 3 slope variance was significant, Coefficient $=0.10, X^{2}(12, N=13)=21.26, p=.046$, indicating that changes in positive parenting, but not intake values of behavior problem frequency, varied across clinicians when accounting for time. Level 2 intercept variance was significant, Coefficient $=34.67, X^{2}(7$, $N=20)=19.59, p=.007$, and level 2 slope variance was not significant, Coefficient $=0.33$, 
$X^{2}(7, N=20)=13.96, p=.051$, indicating that intake behavior problem frequency scores varied across parent-child dyads but changes in frequency did not vary when accounting for time.

Conditional Model. Deviance comparisons indicated that the conditional model significantly improved model fit compared to the intercepts and slopes model, $X^{2}(4, N=108)=$ $13.45, p=.009$. However, the addition of number of PDI sessions as a covariate did not significantly improve the fit of the conditional model, $X^{2}(13, N=108)=21.35, p=.07$. Thus, the number of PDI sessions were not retained in the final model. The conditional model showed that coaching competence significantly predicted behavior problem frequency at intake, Coefficient $=16.36, t(10)=2.80, p=.019$, such that competence was likely to be higher when behavior problems were more "problematic" for parents at the beginning of treatment. However, coaching competence did not predict change in behavior problem frequency over time, Coefficient $=-1.03, t(10)=-1.45, p=.179$. Treatment adherence did not significantly predict behavior problem frequency at intake, Coefficient $=7.10, t(10)=1.00, p=.343$, or change in behavior problem frequency over time, Coefficient $=2.07, t(10)=2.18, p=.054$.

Level 3 intercept variance was not significant, Coefficient $=1.14, X^{2}(10, N=108)=6.90$, $p>.500$, and level 3 slope variance was significant, Coefficient $=0.01, X^{2}(10, N=108)=18.92$, $p=.041$. This suggested that across clinicians there was unexplained variance in the change of behavior problem frequency over time, but not in intake value of behavior problem frequency, when accounting for treatment fidelity. Level 2 intercept variance was significant, Coefficient $=$ $27.14, X^{2}(7, N=108)=18.46, p=.010$, and level 2 slope variance was not significant, Coefficient $=0.09, X^{2}(7, N=108)=11.10, p=.134$, indicating that when accounting for treatment fidelity across parent-child dyads there was more variance in behavior problem frequency at intake across parent-child dyads relative to clinicians, but more variance in behavior problem frequency over time across clinicians relative to parent-child dyads. 
Effects on Positive Parenting. The unconditional model indicated that there were differences in positive parenting (transformed) across groups in the sample, Coefficient $=0.93$, $t(12)=6.24, p<.001$. Level 3 variance was not significant, Coefficient $=0.00, X^{2}(12, N=13)=$ $11.00, p>.500$, suggesting that positive parenting did not vary across clinicians. Level 2 intercept variance was significant, Coefficient $=0.41, X^{2}(13, N=26)=50.52, p<.001$, suggesting that values of positive parenting were different across parent-child dyads. ICC estimates indicated that approximately $53 \%$ of the variation in positive parenting was attributed to within-dyad differences, $47 \%$ was attributed to differences across parent-child dyads, and $0 \%$ was attributed to differences across clinicians. Although grouping at the clinician level did not appear to predict positive parenting skills, multilevel modeling was used to account for differences across dyads.

Intercepts and Slopes Model. Although deviance statistics decreased in the intercepts and slopes model, chi-square comparisons indicated that it did not provide a significantly better model fit than the unconditional model, $X^{2}(5, N=108)=3.50, p>.500$. The intercepts and slopes model indicated that without accounting for additional predictors, positive parenting did not change significantly each month following intake, Coefficient $=-0.02, t(12)=-0.76, p=$ .462. Level 3 intercept variance was not significant, Coefficient $=0.02, X^{2}(12, N=13)=11.48, p$ $>.500$, and level 3 slope variance was significant, Coefficient $=0.00, X^{2}(7, N=13)=21.40, p=$ .045 , indicating that change in positive parenting, but not intake values of positive parenting, varied across clinicians when accounting for time. Level 2 intercept variance was significant, Coefficient $=0.46, X^{2}(8, N=21)=28.72, p<.001$, and level 2 slope variance was not significant, Coefficient $=0.00, X^{2}(8, N=21)=10.97, p=.202$, indicating that positive parenting at intake, but not change in positive parenting over time, differed across parent-child dyads. 
Conditional Model. Although deviance statistics decreased in the conditional model, chisquare comparisons indicated that the conditional model did not significantly improve model fit compared to the intercepts and slopes model, $X^{2}(4, N=108)=4.99, p=.288$, or the unconditional model, $X^{2}(9, N=108)=8.49, p>.500$. Moreover, adding the number of PDI sessions did not improve model fit in the conditional model, $X^{2}(13, N=108)=16.86, p=.205$. Thus, number of PDI sessions attended was not retained in the final model and the output of the conditional model was interpreted with caution. The conditional model indicated that coaching competence did not significantly predict positive parenting at intake, Coefficient $=-0.49, t(10)=$ $-0.76, p=.464$, or change in positive parenting over time, Coefficient $=-0.05, t(10)=-0.66, p=$ .525. Treatment adherence did not predict positive parenting skills at intake, Coefficient $=0.41$, $t(10)=0.50, p=.629$, or change in positive parenting over time, Coefficient $=-0.13, t(10)=-$ $1.42, p=.187$.

Level 3 intercept variance was not significant, Coefficient $=0.00, X^{2}(10, N=108)=$ $10.99, p=.358$, and level 3 slope variance was not significant, Coefficient $=0.00, X^{2}(10, N=$ $108)=13.75, p=.184$. This indicated that when accounting for treatment fidelity, there was no unexplained variance across clinicians in positive parenting at intake or positive parenting change over time. Level 2 intercept variance was significant, Coefficient $=0.45, X^{2}(8, N=108)$ $=28.65, p<.001$, and level 2 slope variance was not significant, Coefficient $=0.00, X^{2}(8, N=$ $108)=11.79, p=.160$. This indicated that there was more variance across parent-child dyads than across clinicians in positive parenting values at intake, but not in positive parenting change over time, when accounting for treatment fidelity.

\section{Interaction Effects of Adherence and Competence}

Interaction effects of clinician treatment adherence and clinician coaching competence on treatment outcomes were assessed by creating a multiplicative interaction term and introducing 
the term as an additional predictor in the conditional models of behavior problem intensity, behavior problem frequency, and positive parenting practices. Fixed and random effects from the interaction models are reported in Table 4, and results are organized by treatment outcome.

Interaction Effects on Behavior Problem Intensity. Fixed intercept effects indicated that there were no significant main effects of competence, Coefficient $=179.56, t(9)=0.90, p=$ .390 , or treatment adherence, Coefficient $=122.54, t(9)=0.83, p=.430$, on behavior problem intensity at intake. There was no significant interaction effect of adherence and competence on behavior problem intensity at intake, Coefficient $=-159.14, t(9)=-0.68, p=.513$. Fixed slope effects indicated that there were no significant main effects of competence, Coefficient $=-5.81$, $t(9)=-0.37, p=.723$, or treatment adherence, Coefficient $=5.40, t(9)=0.45, p=.667$ on behavior problem intensity over time. There was also no significant interaction effect of adherence and competence on behavior problem intensity over time, Coefficient $=2.13, t(9)=$ $0.11, p=.912$. Level 3 random effects suggested unexplained variance in behavior problem intensity at intake, Coefficient $=268.40, X^{2}(9, N=13)=18.95, p=.025$, but not over time, Coefficient $=0.16, X^{2}(9, N=13)=10.03, p=.348$. Level 2 random effects suggested more variance in behavior problem intensity at intake across dyads than across clinicians, Coefficient $=845.24, X^{2}(8, N=21)=24.55, p=.002$, and more variance in behavior problem intensity across dyads over time, Coefficient $=0.02, X^{2}(8, N=21)=20.64, p=.008$.

Interaction Effects on Behavior Problem Frequency. Fixed intercept effects indicated that there were no significant main effects of competence, Coefficient $=67.51, t(9)=1.98, p=$ .079, or treatment adherence, Coefficient $=43.50, t(9)=1.73, p=.118$, on behavior problem frequency at intake. There was no significant interaction effect of adherence and integrity on behavior problem frequency at intake, Coefficient $=-59.85, t(9)=-1,51, p=.164$. Fixed slope effects indicated that there were no significant main effects of competence, Coefficient $=0.63$, 
$t(9)=0.15, p=.886$ or treatment adherence, Coefficient $=3.43, t(9)=1.01, p=.338$ on behavior problem frequency over time. There was no significant interaction effect of behavior problem frequency over time, Coefficient $=-2.17, t(9)=-0.42, p=.687$. Level 3 random effects suggested unexplained variance in behavior problem frequency over time, Coefficient $=0.00$, $X^{2}(9, N=13)=18.91, p=.026$, but not in behavior problem frequency at intake, Coefficient $=$ $0.02, X^{2}(9, N=13)=6.37, p>.500$. Level 2 random effects suggested that there was more unexplained variance in behavior problem frequency at intake across dyads than across clinicians, Coefficient $=24.18, X^{2}(7, N=20)=18.89, p=.009$, but not in behavior problem frequency over time, Coefficient $=0.10, X^{2}(7, N=20)=11.24, p=.128$.

Interaction Effects on Positive Parenting. Fixed intercept effects indicated that there were no significant main effects of competence, Coefficient $=6.60, t(9)=1.77, p=.111$, or treatment adherence, Coefficient $=5.60, t(9)=2.00, p=.076$, on positive parenting at intake. There was no significant interaction effect of adherence and integrity on positive parenting at intake, Coefficient $=-8.45, t(9)=-1.93, p=.086$. Fixed slope effects indicated there were no significant main effects of competence, Coefficient $=-0.18, t(9)=-0.49, p=.702$ or treatment adherence, Coefficient $=-0.23, t(9)=-0.67, p=.522$ on positive parenting over time. There was no significant interaction effect of adherence and integrity on positive parenting over time, Coefficient $=0.15, t(9)=0.27, p=.791$. Level 3 random effects did not suggest significant unexplained variance in positive parenting at intake across clinicians, Coefficient $=0.00, X^{2}(9, N$ $=13)=8.68, p>.500$, or across clinicians over time, Coefficient $=0.00, X^{2}(9, N=13)=13.56, p$ $=.138$. Level 2 random effects did not suggest unexplained variance in positive parenting over time, Coefficient $=0.00, X^{2}(8, N=21)=12.45, p=.132$, but did suggest increased variance in positive parenting at intake across dyads, Coefficient $=0.37, X^{2}(8, N=21)=28.58, p<.001$. 


\section{Discussion}

The current study aimed to investigate relationships between two major components of treatment fidelity in PCIT, treatment adherence and CDI coaching competence, and changes in parent-child outcomes over time. This was the first study to look at the effects of two major facets of fidelity on parent-level (i.e., parenting skill) and child-level (i.e., problem behavior) treatment outcomes in a PCIT implementation trial. This study contributes to the extant literature by assessing whether these fidelity components, as measured by the Treatment Integrity Checklist and the FIRST Coach Coding System, are linearly related to parent-child outcomes at intake and over the months following intake.

The mean level of adherence across clinicians in the current study was about $70 \%$, which is lower than what has been demonstrated in previous studies of PCIT trainees (Travis \& Brestan-Knight, 2013). The mean level of competence across clinicians was approximately $56 \%$. Although these observations are lower than what has been observed in some PCIT trials, they are more similar to studies where parent management training has been implemented in communitybased settings (Breitenstein et al., 2010a).

\section{Adherence Effects}

The current study did not support the hypothesis that treatment adherence would predict changes in behavior problem intensity, behavior problem frequency, and positive parenting skills across time. Additionally, the inclusion of adherence in the conditional models did not predict values of behavior problem intensity, behavior problem frequency, of positive parenting at intake. These findings suggest that clinician adherence to the PCIT treatment manual in early treatment is not associated with change in child behavior problems or positive parenting practices. This finding is similar to several previous studies in other treatment modalities which failed to identify significant relationships between fidelity and outcome severity. A study 
conducted by Boswell and colleagues was unable to predict change in panic symptom severity using measures of adherence and competence for Cognitive Behavioral Therapy (Boswell et al., 2013). In another study of therapist effects on panic symptoms, Huppert and colleagues found that clinicians tended not to vary in their levels of adherence and competence, regardless of client outcomes (Huppert et al., 2001). A separate study utilizing Cognitive Behavioral Therapy for depression found that only some scales on the measure of adherence, but not all, predicted changes in treatment outcomes. Notably, this study also found that client behaviors that either promote or inhibit therapist adherence behaviors had an effect on outcomes (Strunk et al., 2010). Therefore, it is possible that interactions between clients and clinicians, rather than therapist behaviors alone, need to be studied in order to understand the mechanisms of fidelity effects.

Previous research has also demonstrated that curvilinear relationships may exist between treatment adherence and treatment outcomes in psychotherapy interventions such as Cognitive Behavior Therapy and Multidimensional Family Therapy (Barber et al., 2006; Hogue et al., 2008). This suggests that strict adherence to a treatment manual may not predict treatment outcomes as well as moderate, or flexible, manual adherence. Given that a few of the models in the current study did not improve model fit when accounting for predictors, it is possible that a curvilinear relationship exists in PCIT as well, in which case linear effects could be erased by a more appropriate curvilinear data structure.

Another explanation for nonsignificant effects in the current study could be due to weaknesses of the Treatment Integrity Checklist as a measure of adherence. The measure represents a checklist of items that reflect instructions given to the clinician for a typical CDI session in the treatment manual. Due to this structure, each component of the treatment session that is listed on measure is weighted equally, meaning that the exclusion of a component with more significance for treatment outcomes (e.g., practicing skills through coaching, assigning 
homework) would yield the same adherence score as the exclusion of a component with less significance for treatment outcomes (e.g., checking-in with the client). Interrater reliability for the double-coded portion of adherence ratings was also low (50\% agreement), indicating that there may have been substantial error introduced with this measure.

One other consideration is the inconsistency in video quality across videos submitted by clinicians. Specifically, clinician videotaping was inconsistent in terms of total session length and start/stop times. Given that adherence is measured by calculating the ratio between the number of components observed and the number of components possible for the duration observed, differences across videos could affect the denominators of these measures. The incomplete nature of some videos submitted by clinicians could partially explain why adherence did not predict outcomes. For example, if videos did not contain check-in or check-out portions of the session and the therapist forgot to assign homework during the check-out period, these portions would not be considered in the ratio and a moderately adherent video could be incorrectly coded as $100 \%$ adherent. Alternately, if videos were submitted where therapists were more adherent to the check-in and check-out procedures than to the coaching procedures that are reflected in the video, it would be incorrectly coded as having lower adherence.

\section{Competence Effects}

The current study did not support the hypothesis that coaching competence would predict changes in behavior problem intensity, behavior problem frequency, and positive parenting skills across time. The inclusion of CDI coaching competence in the conditional models did not predict values of behavior problem intensity or positive parenting at intake. However, CDI coaching competence did predict behavior problem frequency at intake, such that clinicians who displayed greater levels of coaching competence were more likely to treat parent-child dyads who presented with behaviors that were more "problematic" for the parent. One explanation for this 
finding is that clinicians respond to more demanding clinical cases with greater coaching quality in the early stages of treatment in response to their perception of a "challenging" case. Another explanation is that more severe cases are taken by therapists with more experience or skill, which could be associated with higher levels of coaching competence.

One rationale for the lack of association between PCIT competence and other treatment outcomes could be that families in community settings are less likely to be receiving large doses of treatment due to higher rates of attrition (Armbruster \& Kazdin, 1994). A study by Trepka and colleagues that assessed competence in Cognitive Therapy for depression noted stronger predictions of treatment outcomes for clients who had graduated from treatment (Trepka et al., 2004).

While the adherence measure selected for the current study represents the training standard in PCIT and is featured in the current treatment manual for PCIT (Eyberg \& Funderburk, 2011), the measure of coaching competence selected is not the only available measure for assessing this construct, and much work is still needed in the psychometric evaluation of these assessments (Davis III \& Brestan-Knight, 2018). Alternate assessments of coaching competence, such as the Therapist-Parent Interaction Coding System (TPICS; Barnett, Davis, Schoonover, \& Niec, 2018) have been featured in more published research than the FIRST Coach Coding System. Thus, it is possible that the competence measure employed in the current study was not the best possible measure for assessing this construct. Although coaching competency is one of the more thoroughly evaluated areas of competence in PCIT training, there are other competencies needed in the delivery of PCIT that occur outside of parent coaching. Not all of these competencies are specific to PCIT. For example, therapists should have sufficient knowledge of how behavioral theories work in treatment to produce change. Additionally, therapists should have competency in assigning appropriate homework (i.e., assessing feasibility 
of assignments) and developing rapport with families early on in treatment. Thus, the measures that are used to assess competence in the current study may not have tapped into the construct of competence fully enough to account for meaningful variance in treatment outcomes.

\section{Interaction Effects}

The current findings did not support the hypothesis that the relationship between treatment adherence and treatment outcomes would be moderated by clinician coaching competence. This was consistent with another trial in which clinician competence was not found to moderate the relationship between adherence and outcome in family therapy services for adolescent behavior problems (Hogue et al., 2008). Changes in behavior problem intensity, behavior problem frequency, and positive parenting skills over time as a function of adherence and competence values are shown in Figure 2, Figure 3, and Figure 4, respectively. Although these effects were not significant, it was noted through visual inspection of the data that higher levels of competence tended to occur when behavior problem intensity and behavior problem frequency was higher at intake. Similarly, competence tended to be higher when positive parenting skills were lower at intake. Random effects from these models suggested that there was more variation in intake scores and trajectories across parent-child dyads than across clinicians. These findings suggest that coaching competence alone does not account for significant variance in the relationship between adherence and competence above and beyond other clinician- and dyad-level factors. Further, the random effects suggest that additional covariates at the parentchild dyad level (e.g., therapeutic alliance, engagement) should be explored.

It should also be considered that the interaction models introduced a third predictor (i.e., the interaction term), adding additional parameters to the conditional model. Thus, the lack of significant interaction effects may be explained by lowered statistical power in the analyses to identify significant effects due to an increased number of parameters. Further, the introduction of 
the interaction term multiplied existing measurement error in the Treatment Integrity Checklist and the FIRST Coach Coding System, increasing the amount of residual error in the interaction model.

\section{Limitations}

Several limitations were present in the current study. One limitation was that the current study only assessed therapist fidelity factors in early treatment sessions. Early treatment fidelity was used as a predictor in the current study as an estimate of fidelity over time. However, visual inspection of the data in the current study suggested that clinicians do not demonstrate similar levels of adherence and competence across all parent-child dyads. Thus, fidelity may need to be assessed at several time points in order to arrive at a reasonable estimate of a clinician's fidelity behaviors. Longitudinal assessment of fidelity would also have increased confidence that the therapist behaviors are accounting for change in the observed outcomes.

A small sample of available videos in the archival data that had been coded for adherence and competence limited the number of clinicians accounted for in the data to 17 , the number of families accounted for to 32, and yielded a small number of families nested within each clinician with some clinicians only representing one distinct family. These circumstances lead to a model which likely did not have sufficient power to detect true effects in the data and increased the likelihood of Type II error. Thus, it is possible that some of the observed effects that were approaching significance would appear as significant effects in future studies featuring a larger sample of videos.

The data that was collected for families represented in the current study also featured a substantial percent of missingness, which is common in community-based research (Bolland, Tomek, \& Bolland, 2017). Although Little's MCAR test did not indicate that the missingness in the current data was related to any particular variable that was accounted for in the dataset, this 
missingness could affect the accuracy of estimates reported in the models. Given that estimation methods must be used in this type of modeling to replace missing values, it is ideal to maximize the number of families that completed outcome assessments at more than one timepoint, as this would improve the accuracy of growth trajectory estimates (Curran et al., 2012).

The small sample of videos and the large percentage of missingness across the treatment outcomes prevented the inclusion of theoretically meaningful covariates that should be controlled to assess a more accurate model of treatment fidelity effects. However, the random effects observed in the conditional model indicated that there was substantial remaining variance across clinicians and parent-child dyads after accounting for treatment fidelity. Including additional variables at the clinician and parent-child levels of analysis could help control for the unexplained variance in these models and improve model fit.

Notably, positive parenting as assessed by the APQ-9 Short Form was not found to change, or vary significantly, across time. The lack of effect of adherence and competence observed on positive parenting may have been due to this outcome not changing across time, since linear change was needed to detect predictors in the conditional models.

It is also unknown whether clinicians who submitted videos to the research team were more likely to have greater levels of adherence or coaching competence compared to those who do not submit videos. This information could not be determined, as the methods used for assessing adherence and competence relied on voluntary video submissions from therapists. However, it is possible that voluntary submission of videos for coding might have resulted in therapists self-selecting the videos that were sent to the research team. If this were the case, treatment adherence and coaching competence may not have varied across clinicians in the current sample in the same way that they would in a truly representative sample of the parent study. 


\section{Strengths}

Although the current study contained several limitations, there were also notable strengths in the study as well. One strength is that the current study utilized an analysis which accounted for nesting within the data. By accounting for the nested data structure (i.e., shared variance within clinicians and within families), bias from incorrectly assuming independence of observations was avoided. Additionally, the multilevel model utilized repeated measures data, which facilitated the examination of fidelity effects both within and across parent-child dyads. This model identified specific levels of analysis where additional variance in the relationship between PCIT fidelity and treatment outcomes may be explored. The current study also examined fidelity-outcome relations for two types of fidelity simultaneously, which has not yet been studied in the PCIT literature. Although a relationship between fidelity and outcomes was not established, this research highlights important issues with current measures that are used for assessing PCIT fidelity. These issues may be leveraged as part of a rationale to develop more effective and pragmatic methods for capturing these constructs.

\section{Future Research}

Future research should continue to assess treatment adherence and clinician competencies as predictors of treatment outcomes along with theoretically meaningful covariates in a larger sample of clinicians and dyads. Increasing the sample size in a future replication would allow investigators to control for more variables that could reduce unexplained variability across clinicians and parent-child dyads in the conditional models. A future replication from the same parent study might include re-sampling all codable CDI videos and re-coding those videos for adherence and competence using a small team of coders. Interrater reliability estimates for each measure should be calculated during the coding process so that the investigators can speak to quality of these measures. 
There are several additional constructs that should be considered for inclusion in future studies of fidelity-outcome relations in community-based PCIT. Families that seek care in community-based settings, such as those represented in the current study, often have limited access to transportation, funds, and time to commit to treatment on a regular basis (Armbruster $\&$ Kazdin, 1994). Families in these settings are also more likely to experience significant life stressors that interfere with treatment compliance (Owens et al., 2002). Given the evidence that treatment engagement can play an important role in promoting treatment outcomes in parenting programs (Baydar, Reid, \& Webster-Stratton, 2003; Haine-Schlagel \& Walsh, 2015), measures that capture variability in treatment engagement, such as barriers to treatment (i.e., substantial life stressors, perceived treatment efficacy, perceived relevance of treatment, relationship with therapist), attrition, and homework completion could explain some variation in treatment outcomes for community-based populations. Therapeutic alliance, or the working relationship between a clinician and their client, has also been demonstrated to be a potential moderator in the relationship between competence and treatment outcome (Despland et al., 2009) as well as in the relationship between adherence and treatment outcome (Barber et al., 2006). Similarly, collaboration between clinicians and clients during sessions has been demonstrated to predict improvements in therapy (Serralta et al., 2010). Therapeutic relationship factors have also been identified as important predictors of treatment outcomes for youth in a meta-analytic review of 49 treatment studies (Karver et al., 2006). Thus, measures of therapeutic alliance should be considered when assessing relationships between fidelity and outcomes in PCIT.

Additional studies should also investigate the relationship between fidelity components and additional outcomes, such as parenting stress and specific externalizing behaviors, such as aggression. Although the ECBI assesses a wide array of problematic child behaviors, it is possible that effects of fidelity are limited to specific clinical presentations. Future studies should 
also consider modeling different types of relationships between fidelity and outcomes, such as curvilinear effects. Other studies have identified curvilinear relationships between adherence and treatment outcomes in other treatment models, such as Cognitive Behavior Therapy (Barber et al., 2006); however, this effect has not been tested in PCIT.

Future research should also investigate the psychometric properties of various measures of PCIT adherence and competence to ensure that these tools capture content that is needed to elicit behavior change. The lack of observed effect of adherence and competence on treatment outcomes in the current study could have been due in part to these measures either not reflecting essential components that are necessary for parent-child change or not being sensitive enough to meaningful changes in adherence and competence. Even when fidelity criteria are clearly defined, reliable and valid observations of fidelity can be difficult to obtain in clinical practice. (Perepletchikova \& Kazdin, 2005). In community settings, there is a competing need for fidelity measures to be both effective (i.e., reflective of actual practice and the culture of the service setting) and efficient (i.e., feasible for clinicians to use). On one hand, objective measures of fidelity that do not rely on clinician report are time consuming and costly to implement. On the other hand, self-reported fidelity measures can be biased and aversive to providers who are burdened by other clinical responsibilities (Schoenwald et al., 2011). Such obstacles frequently affect the validity of fidelity outcomes that are collected in community-based research. Given the difficult of collecting therapy videos from clinicians for the purpose of fidelity coding, future studies could also explore alternative methods for assessing this construct that do not rely solely on the clinician's self-report.

\section{Conclusion}

Treatment adherence and competence are important constructs in implementation research that should be assessed to determine whether trained clinicians are administering 
treatments as intended. The current study suggests that early session measures of treatment adherence and coaching competence in a community treatment setting do not predict changes in parent-child outcomes without accounting for additional family factors or changes in fidelity over time. However, clinicians are more likely to demonstrate coaching competencies when parents report behavior problems as being more frequent at intake. Future research should examine the effects of treatment fidelity alongside additional family-level factors, such as barriers to treatment engagement and therapeutic alliance. Measurement of fidelity over time should also be considered in future studies as an alternative to early session fidelity. Finally, measures of treatment fidelity that are employed in PCIT implementation should be assessed to ensure that they reflect core components of treatment that are needed to elicit treatment gains. 


\section{References}

Aarons, G. A., Hurlburt, M., \& Horwitz, S. M. (2011). Advancing a conceptual model of evidence-based practice implementation in public service sectors. Administration and Policy in Mental Health and Mental Health Services Research, 38(1), 4-23.

Armbruster, P., \& Kazdin, A. E. (1994). Attrition in child psychotherapy. Advances in Clinical Child Psychology (pp. 81-108). Springer, Boston, MA.

Barber, J. P., Gallop, R., Crits-Christoph, P., Frank, A., Thase, M. E., Weiss, R. D., \& Beth Connolly Gibbons, M. (2006). The role of therapist adherence, therapist competence, and alliance in predicting outcome of individual drug counseling: Results from the National Institute Drug Abuse Collaborative Cocaine Treatment Study. Psychotherapy Research, 16(2), 229-240.

Barber, J. P., Sharpless, B. A., Klostermann, S., \& McCarthy, K. S. (2007). Assessing intervention competence and its relation to therapy outcome: A selected review derived from the outcome literature. Professional Psychology: Research and Practice, 38(5), 493.

Barnett, M. L., Davis, E. M., Schoonover, C. E., \& Niec, L. N. (2018). Therapist-Parent Interactions in PCIT: The Importance of Coach Coding. In Handbook of Parent-Child Interaction Therapy (pp. 303-317). Springer, Cham.

Barnett, M. L., Niec, L. N., \& Acevedo-Polakovich, I. D. (2014). Assessing the key to effective coaching in parent-child interaction therapy: The therapist-parent interaction coding system. Journal of Psychopathology and Behavioral Assessment, 36(2), 211-223.

Barnett, M. L., Niec, L. N., Peer, S. O., Jent, J. F., Weinstein, A., Gisbert, P., \& Simpson, G. (2017). Successful therapist-parent coaching: How in vivo feedback relates to parent engagement in parent-child interaction therapy. Journal of Clinical Child \& Adolescent Psychology, 46(6), 895-902. 
Baydar, N., Reid, M. J., \& Webster-Stratton, C. (2003). The role of mental health factors and program engagement in the effectiveness of a preventive parenting program for Head Start mothers. Child development, 74(5), 1433-1453.

Boisjoli, R., Vitaro, F., Lacourse, E., Barker, E. D., \& Tremblay, R. E. (2007). Impact and clinical significance of a preventive intervention for disruptive boys: 15-year follow-up. The British Journal of Psychiatry, 191(5), 415-419.

Bolland, A. C., Tomek, S., \& Bolland, J. M. (2017). Does Missing Data in Studies of Hard-toReach Populations Bias Results? Not Necessarily. Open Journal of Statistics, 7(02), 264. Boswell, J. F., Gallagher, M. W., Sauer-Zavala, S. E., Bullis, J., Gorman, J. M., Shear, M. K., ... \& Barlow, D. H. (2013). Patient characteristics and variability in adherence and competence in cognitive-behavioral therapy for panic disorder. Journal of Consulting and Clinical Psychology, 81(3), 443.

Breitenstein, S. M., Fogg, L., Garvey, C., Hill, C., Resnick, B., \& Gross, D. (2010a). Measuring implementation fidelity in a community-based parenting intervention. Nursing Research, $59(3), 158$.

Breitenstein, S. M., Gross, D., Garvey, C. A., Hill, C., Fogg, L., \& Resnick, B. (2010b). Implementation fidelity in community-based interventions. Research in Nursing \& Health, 33(2), 164-173.

Broidy, L. M., Nagin, D. S., Tremblay, R. E., Bates, J. E., Brame, B., Dodge, K. A., Fergusson, D., Horwood, J. L., Loeber, R., Laird, R., Lynam, D. R., Moffitt, T. E., Pettit, G. S., \& Vitaro, F. (2003). Developmental trajectories of childhood disruptive behaviors and adolescent delinquency: a six-site, cross-national study. Developmental Psychology, 39(2), 222. 
Bryk, A. S., \& Raudenbush, S. W. (1992). Hierarchical linear models for social and behavioral research: Applications and data analysis methods. Thousand Oaks, CA, US: Sage Publications, Inc.

Budd, K. S., Hella, B., Bae, H., Meyerson, D. A., \& Watkin, S. C. (2011). Delivering parentchild interaction therapy in an urban community clinic. Cognitive and Behavioral Practice, 18(4), 502-514.

Caron, E. B., Bernard, K., \& Dozier, M. (2016). In vivo feedback predicts parent behavior change in the Attachment and Biobehavioral Catch-up intervention. Journal of Clinical Child \& Adolescent Psychology, 1-12.

Carpenter, A. L., Puliafico, A. C., Kurtz, S. M., Pincus, D. B., \& Comer, J. S. (2014). Extending parent-child interaction therapy for early childhood internalizing problems: New advances for an overlooked population. Clinical Child and Family Psychology Review, 17(4), 340-356.

Caspi, A., Moffitt, T. E., \& Newman, D. L. (1998). Behavioral Observations at Age 3 Years Predict Adult Psychiatric Disorders: Longitudinal. Annual Progress in Child Psychiatry and Child Development 1997, 319.

Chambers, D. A., Glasgow, R. E., \& Stange, K. C. (2013). The dynamic sustainability framework: addressing the paradox of sustainment amid ongoing change. Implementation Science, 8(1), 117.

Comer, J. S., Furr, J. M., Miguel, E. M., Cooper-Vince, C. E., Carpenter, A. L., Elkins, R. M., Kerns, C. E., Cornacchio, D., Chou, T., Coxe, S., DeSerisy, M., Sanchez, A. L., Golik, A., Martin, J., Myers, K. M., \& Chase, R. (2017). Remotely delivering real-time parent training to the home: An initial randomized trial of Internet-delivered parent-child interaction therapy (I-PCIT). Journal of Consulting and Clinical Psychology, 85(9), 909. 
Curran, G. M., Bauer, M., Mittman, B., Pyne, J. M., \& Stetler, C. (2012). Effectivenessimplementation hybrid designs: combining elements of clinical effectiveness and implementation research to enhance public health impact. Medical Care, 50(3), 217.

Curran, P. J., Obeidat, K., \& Losardo, D. (2010). Twelve frequently asked questions about growth curve modeling. Journal of Cognition and Development, 11(2), 121-136.

Davis III, R. F., \& Brestan-Knight, E. (2018). Assessing Therapist Competence in the Context of PCIT Training. In Handbook of Parent-Child Interaction Therapy (pp. 319-339). Springer, Cham.

Despland, J. N., de Roten, Y., Drapeau, M., Currat, T., Beretta, V., \& Kramer, U. (2009). The role of alliance in the relationship between therapist competence and outcome in brief psychodynamic psychotherapy. The Journal of Nervous and Mental Disease, 197(5), 362-367.

Eiraldi, R., Mautone, J. A., Khanna, M. S., Power, T. J., Orapallo, A., Cacia, J., Schwartz, B.S., McCurdy, B., Keiffer, J., Paidpati, C., Kanine, R., Abraham, M., Tulio, S., Swift, L., Bressler, S. N., Cabello, B., \& Jawad, A.F. (2018). Group CBT for externalizing disorders in urban schools: Effect of training strategy on treatment fidelity and child outcomes. Behavior Therapy.

Eyberg, S. M., \& Pincus, D. (1999). ECBI \& SESBI-R: Eyberg child behavior inventory and Sutter-Eyberg student behavior inventory-revised: Professional manual. Psychological Assessment Resources.

Eyberg, S., \& Funderburk, B. (2011). Parent-Child Interaction Therapy protocol. PCIT International. Inc. Gainesville, FL. 
Forgatch, M. S., Patterson, G. R., \& DeGarmo, D. S. (2005). Evaluating fidelity: Predictive validity for a measure of competent adherence to the Oregon model of parent management training. Behavior Therapy, 36(1), 3-13.

Galanter, R., Self-Brown, S., Valente, J. R., Dorsey, S., Whitaker, D. J., Bertuglia-Haley, M., \& Prieto, M. (2012). Effectiveness of parent-child interaction therapy delivered to at-risk families in the home setting. Child \& Family Behavior Therapy, 34(3), 177-196.

Haine-Schlagel, R., \& Walsh, N. E. (2015). A review of parent participation engagement in child and family mental health treatment. Clinical Child and Family Psychology Review, 18(2), 133-150.

Herschell, A. D. (2010). Fidelity in the field: developing infrastructure and fine-tuning measurement. Clinical Psychology: Science and Practice, 17(3), 253-257.

Herschell, A. D., Kolko, D. J., Scudder, A. T., Taber-Thomas, S., Schaffner, K. F., Hiegel, S. A., Iyengar, S., Chaffin, M., \& Mrozowski, S. (2015). Protocol for a statewide randomized controlled trial to compare three training models for implementing an evidence-based treatment. Implementation Science, 10(1), 133.

Hoagwood, K., Burns, B. J., Kiser, L., Ringeisen, H., \& Schoenwald, S. K. (2001). Evidencebased practice in child and adolescent mental health services. Psychiatric Services, 52(9), 1179-1189.

Hoagwood, K., \& Olin, S. S. (2002). The NIMH blueprint for change report: Research priorities in child and adolescent mental health. Journal of the American Academy of Child \& Adolescent Psychiatry, 41(7), 760-767.

Hogue, A., Dauber, S., Chinchilla, P., Fried, A., Henderson, C., Inclan, J., ... \& Liddle, H. A. (2008). Assessing fidelity in individual and family therapy for adolescent substance abuse. Journal of Substance Abuse Treatment, 35(2), 137-147. 
Huppert, J. D., Bufka, L. F., Barlow, D. H., Gorman, J. M., Shear, M. K., \& Woods, S. W. (2001). Therapists, therapist variables, and cognitive-behavioral therapy outcome in a multicenter trial for panic disorder. Journal of Consulting and Clinical Psychology, 69(5), 747.

Karver, M. S., Handelsman, J. B., Fields, S., \& Bickman, L. (2006). Meta-analysis of therapeutic relationship variables in youth and family therapy: The evidence for different relationship variables in the child and adolescent treatment outcome literature. Clinical Psychology Review, 26(1), 50-65.

Kazdin, A. E., \& Nock, M. K. (2003). Delineating mechanisms of change in child and adolescent therapy: Methodological issues and research recommendations. Journal of Child Psychology and Psychiatry, 44(8), 1116-1129.

Kazdin, A. E. (2018). Implementation and evaluation of treatments for children and adolescents with conduct problems: findings, challenges, and future directions. Psychotherapy Research, 28(1), 3-17.

Kaminski, J. W., \& Claussen, A. H. (2017). Evidence base update for psychosocial treatments for disruptive behaviors in children. Journal of Clinical Child \& Adolescent Psychology, 46(4), 477-499.

Lesack, R., Bearss, K., Celano, M., \& Sharp, W. G. (2014). Parent-Child Interaction Therapy and autism spectrum disorder: Adaptations with a child with severe developmental delays. Clinical Practice in Pediatric Psychology, 2(1), 68.

Lyon, A. R., \& Budd, K. S. (2010). A community mental health implementation of parent-child interaction therapy (PCIT). Journal of Child and Family Studies, 19(5), 654-668. 
McHugh, R. K., Murray, H. W., \& Barlow, D. H. (2009). Balancing fidelity and adaptation in the dissemination of empirically-supported treatments: The promise of transdiagnostic interventions. Behaviour Research and Therapy, 47(11), 946-953.

Mihalic, S. (2004). The importance of implementation fidelity. Emotional and Behavioral Disorders in Youth, 4(4), 83-105.

Miller, S. J., \& Binder, J. L. (2002). The effects of manual-based training on treatment fidelity and outcome: A review of the literature on adult individual psychotherapy. Psychotherapy: Theory, Research, Practice, Training, 39(2), 184.

Nelson, T. D., \& Steele, R. G. (2007). Predictors of practitioner self-reported use of evidencebased practices: Practitioner training, clinical setting, and attitudes toward research. Administration and Policy in Mental Health and Mental Health Service Review, 34, 319-330

Nezu, A. M., Nezu, C. M., \& McKay, D. (2008). Treatment integrity. Handbook of research methods in abnormal and clinical psychology, 351-363.

Niec, L. N., Barnett, M. L., Prewett, M. S., \& Shanley Chatham, J. R. (2016). Group parentchild interaction therapy: A randomized control trial for the treatment of conduct problems in young children. Journal of Consulting and Clinical Psychology, 84(8), 682.

Owens, P. L., Hoagwood, K., Horwitz, S. M., Leaf, P. J., Poduska, J. M., Kellam, S. G., \& Ialongo, N. S. (2002). Barriers to children's mental health services. Journal of the American Academy of Child \& Adolescent Psychiatry, 41(6), 731-738.

Perepletchikova, F., \& Kazdin, A. E. (2005). Treatment integrity and therapeutic change: Issues and research recommendations. Clinical Psychology: Science and Practice, 12(4), 365383. 
Perepletchikova, F., Treat, T. A., \& Kazdin, A. E. (2007). Treatment integrity in psychotherapy research: analysis of the studies and examination of the associated factors. Journal of Consulting and Clinical Psychology, 75(6), 829.

Perou, R., Bitsko, R. H., Blumberg, S. J., Pastor, P., Ghandour, R. M., Gfroer, J. C., \& Huang, L.N. (2013). Mental health surveillance among children - United States, 20052011. Morbidity and Mortality Weekly Report, 62(Suppl. 2), 1-35.

President's New Freedom Commission on Mental Health. (2003). Achieving the promise: Transforming Mental Health in America. Final report. Rockville, MD: DHHS Publication.

Proctor, E. K., Landsverk, J., Aarons, G., Chambers, D., Glisson, C., \& Mittman, B. (2009). Implementation research in mental health services: an emerging science with conceptual, methodological, and training challenges. Administration and Policy in Mental Health and Mental Health Services Research, 36(1), 24-34.

Proctor, E., Silmere, H., Raghavan, R., Hovmand, P., Aarons, G., Bunger, A., Griffey, R., \& Hensley, M. (2011). Outcomes for implementation research: conceptual distinctions, measurement challenges, and research agenda. Administration and Policy in Mental Health and Mental Health Services Research, 38(2), 65-76.

Regan, J., Daleiden, E. L., \& Chorpita, B. F. (2013). Integrity in mental health systems: An expanded framework for managing uncertainty in clinical care. Clinical Psychology: Science and Practice, 20(1), 78-98.

Rubenstein, L. V., \& Pugh, J. (2006). Strategies for promoting organizational and practice change by advancing implementation research. Journal of General Internal Medicine, 21(S2). 
Schoenwald, S. K. (2011). It's a bird, it's a plane, it's... fidelity measurement in the real world. Clinical Psychology: Science and Practice, 18(2), 142-147.

Schoenwald, S. K., Garland, A. F., Chapman, J. E., Frazier, S. L., Sheidow, A. J., \& SouthamGerow, M. A. (2011). Toward the effective and efficient measurement of implementation fidelity. Administration and Policy in Mental Health and Mental Health Services Research, 38(1), 32-43.

Serralta, F. B., Pole, N., Tiellet Nunes, M. L., Eizirik, C. L., \& Olsen, C. (2010). The process of change in brief psychotherapy: Effects of psychodynamic and cognitive-behavioral prototypes. Psychotherapy Research, 20(5), 564-575.

Strunk, D. R., Brotman, M. A., \& DeRubeis, R. J. (2010). The process of change in cognitive therapy for depression: Predictors of early inter-session symptom gains. Behaviour Research and Therapy, 48(7), 599-606.

Tremblay, R. E., Pihl, R. O., Vitaro, F., \& Dobkin, P. L. (1994). Predicting early onset of male antisocial behavior from preschool behavior. Archives of General Psychiatry, 51(9), 732739.

Tremblay, R. E., Masse, B., Perron, D., LeBlanc, M., Schwartzman, A. E., \& Ledingham, J. E. (1992). Early disruptive behavior, poor school achievement, delinquent behavior, and delinquent personality: longitudinal analyses. Journal of Consulting and Clinical Psychology, 60(1), 64.

Trepka, C., Rees, A., Shapiro, D. A., Hardy, G. E., \& Barkham, M. (2004). Therapist competence and outcome of cognitive therapy for depression. Cognitive Therapy and Research, 28(2), 143-157. 
Vitaro, F., Brendgen, M., Larose, S., \& Tremblay, R. E. (2005). Kindergarten disruptive behaviors, protective factors, and educational achievement by early adulthood. Journal of Educational Psychology, 97(4), 617.

Ward, M. A., Theule, J., \& Cheung, K. (2016, October). Parent-child interaction therapy for child disruptive behaviour disorders: A meta-analysis. In Child \& Youth Care Forum (Vol. 45, No. 5, pp. 675-690). Springer US.

Waltz, J., Addis, M. E., Koerner, K., \& Jacobson, N. S. (1993). Testing the integrity of a psychotherapy protocol: assessment of adherence and competence. Journal of Consulting and Clinical Psychology, 61(4), 620.

Webb, C. A., DeRubeis, R. J., \& Barber, J. P. (2010). Therapist adherence/competence and treatment outcome: A meta-analytic review. Journal of Consulting and Clinical Psychology, 78(2), 200.

Weisz, J., Donenburg, G., Han, S., \& Weiss, B. (1995). Bridging the gap between laboratory and clinic in child and adolescent psychology. Journal of Consulting and Clinical Psychology, 63, 688-701. 


\section{Appendix A: Measures}

\section{$\underline{\text { Trainer-Completed Measures }}$}

- Treatment Integrity Checklist for CDI

- FIRST Coach Coding System for CDI in PCIT (FCCS-CDI)

$\underline{\text { Clinician-Completed Measures }}$

- Clinician Background and Contact Information Form

- Treatment Summary Report (TSR)

\section{$\underline{\text { Parent-Completed Measures }}$}

- Demographics Information Form (Family)

- Eyberg Child Behavior Inventory (ECBI)

- Alabama Parenting Questionnaire, Short Form (APQ-9) 


\section{Treatment Integrity Checklist for CDI Coach 2 Session}

Name Session \#

Date

Rater

As you view the session, place a checkmark under the appropriate column.

ust these totals in the appropriate blanks below the table. See expanded session outlines for more information on each item.

ITEM

- Spend a few minutes addressing parent stressors unrelated to the child's behavior

4 Review homework sheets for about 5 minutes With one parent in treatment

- Code parent and child in CDI for 5 minutes

- Give parent feedback on skills and set goals for coaching

- Coach parent with child for at least 20 minutes

With two parents in treatment

Code first parent and child CDI for 5 minutes

Give first parent feedback on skills and set goals for coaching

Coach first parent with child for at least 10 minutes

Code second parent for 5 minutes

Give second parent feedback on skills and set goals for coaching

Coach second parent with child for at least 5 minutes

With each parent

Review CDI Skills Progress sheet data

- Describe the mastery criteria for CDI

Show parents the ECBI graph

1

Give homework sheets and discuss with parents

TOTALS

Therapist Comments about Session

integrity Checker Comments about Session

integrity $=\frac{\text { Yes's }\left(V^{\prime} s\right)}{\text { Yes's }\left(V^{\prime} s\right)+\text { No's }\left(X^{\prime} s\right)} \quad \%$

Lencth of session a minutes

Nate. Omit items not applicable (1.e., 1-parent items for 2-parent family and vice versa)

esamove 2ait peri hteinationa, inc. 
CODING THE COACH: PROJECT FIRST

DATE:

PCIT SESSION:

TRAINEE:

CODER:

POSITIVE COACHING STATEMENTS

TALLY

TOTAL

HIGHER ORDER STATEMENTS

(HO)

DESCRIPTION OF:

\begin{tabular}{r|r|r|} 
Child (DCh) & & \\
\hline Parent (DP) & & \\
\hline Skill/toy/situation (DS) & & \\
\hline
\end{tabular}

Total

Descriptions:

LABELED PRAISE (LP) (includes CLP*) for caregiver use of:

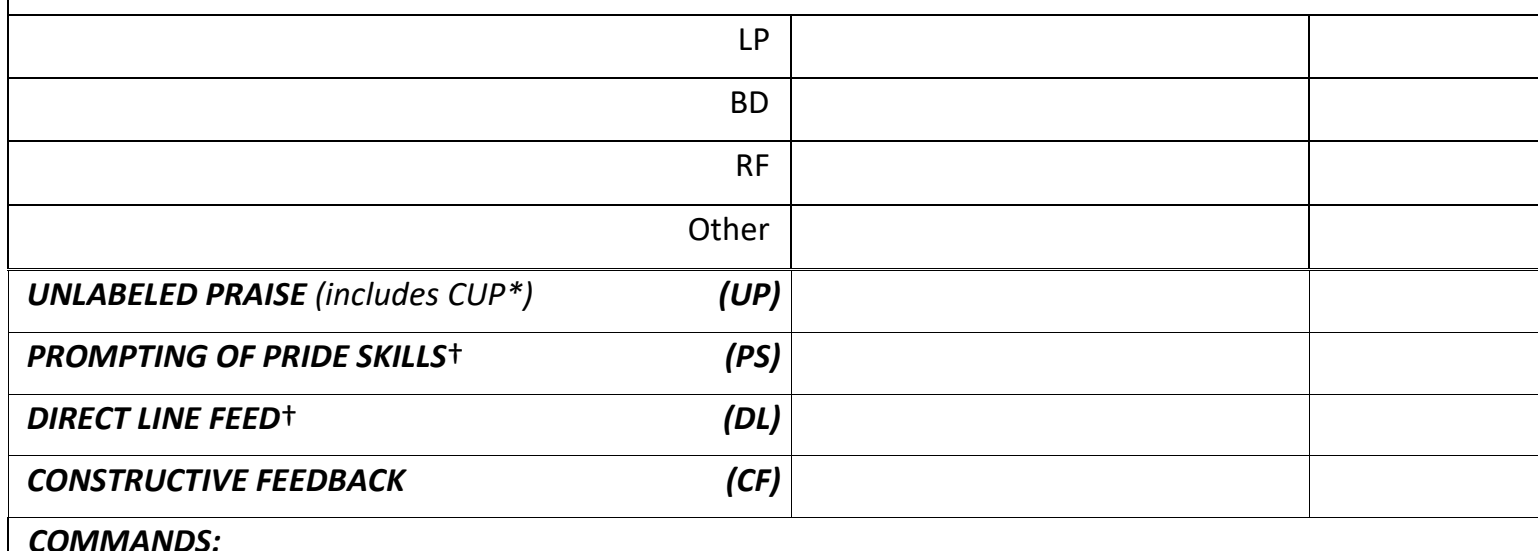

Total Praise:

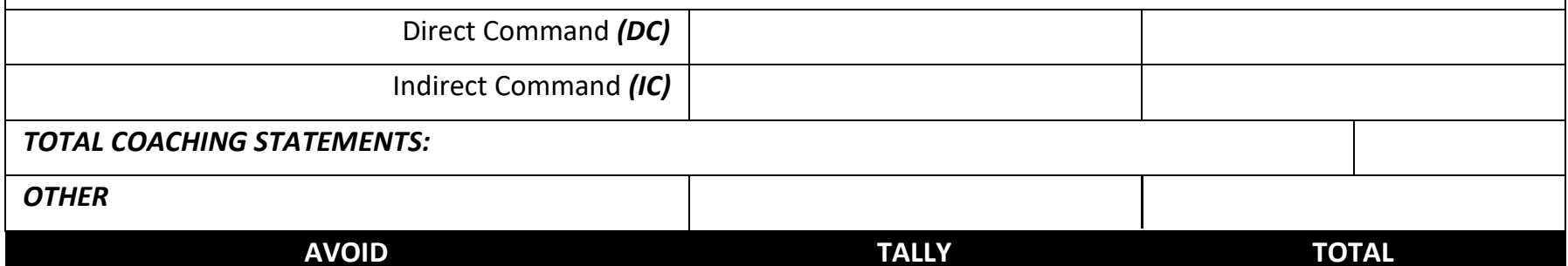

COACHING ERRORS (CE):

\begin{tabular}{|r|r|r|}
\hline Mislabeling Parent PRIDE Skills & & \\
\hline Inappropriate Suggestions & & \\
\hline Criticism or Irrelevant Remarks & & \\
\hline
\end{tabular}

Total CE:

\section{MISSED OPPORTUNITIES (MO):}

Missed Praise for Spontaneous LP, BD, RF Missed Contingent Praise for PS, DL

LIST THERAPIST'S IDENTIFIED COACHING GOAL(S):

ON A SCALE OF 1-4, RATE COACH'S ADHERENCE TO GOAL(S):
ON A SCALE OF 1-4, RATE COACH'S ENTHUSIASM/MATCHING :

*Circle tally mark if it is contingent $L P(C L P)$ or contingent UP (CUP). + Circle tally mark if caregiver follows PS or DL

\section{Criterion}

\section{Score}

Yes

No
Stylistic Features (circle number if met) 


\begin{tabular}{|l|l|l|l|}
\hline Total coaching statements $\geq 35$ & & & 1. Praise Other $\geq 2$ \\
\hline$\geq 10$ Praise & & & 2. Missed Praise $\leq 1 / 2$ spont. LP, RF, BD \\
\hline$\geq 1 / 2(50 \%)$ Praise Labeled & & & 3. Contingent Praise $\geq 1 / 2$ opportunities \\
\hline$\leq 3$ Coaching Errors & & 4. DL $\leq 1 / 4$ of total coaching statements \\
\hline $4 / 7$ Stylistic Features & & 5. DCh, DP, DS $\geq 5$ \\
\hline MET CDI COACHING MASTERY & & 6. CF $\leq 1 / 10$ of total coaching statements \\
\hline
\end{tabular}




\section{Clinician Background and Contact Information Form}

Please answer the following questions about your demographic information, your professional background, and your current job.

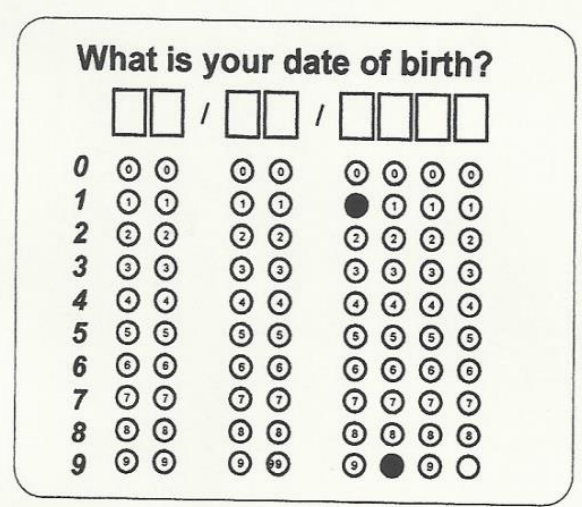

What is your Gender?

O Male

O Female

What is your Ethnicity?

O Hispanic or Latino

O Not Hispanic or Latino

What is your Race?

(Fill in all that apply)

O American Indian/Alaska Native

O Asian

O Native Hawaiian or other Pacific Islander

O Black or African American

OWhite

O More than one Race

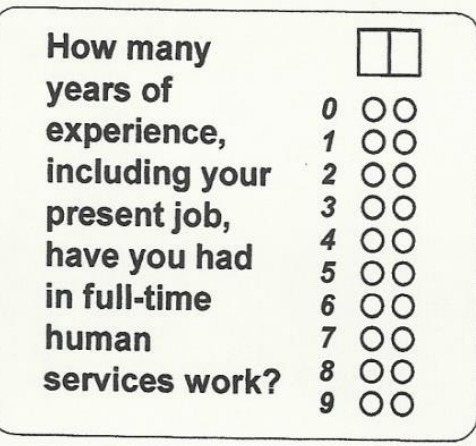

\begin{tabular}{|lc|}
\hline How many & $\square$ \\
years have & 000 \\
you worked & 100 \\
in your & 200 \\
present & 300 \\
agency? & 400 \\
& 500 \\
& 600 \\
& 700 \\
& 800 \\
& 900 \\
\hline
\end{tabular}

Your highest level degree is in:

What level of education
have you completed?

O High school graduate

O Some college

O Bachelors degree

O Some graduate work

O Masters degree

O Doctoral degree

Please Answer BOTH the

Ethnicity AND Race fields.
O Education

O Medicine

O Nursing

O Psychology

O Social Work

O Other

What is your current role? (Fill in all that apply)

O Assessment Clinician

O Intake Coordinator

O Program Support
O Supervisor

O Treatment Clinician

O Other, please specify: 
1. Are you professionally licensed (e.g., psychology or social work license?) O Yes O No Please indicate type of license: O LPC O LSW O LCSW O Psychologist O Other, please specify:

2. Setting where you do the majority of your work:

O Client's homes

O Your agency

O Group home/residential

O Other, please specify:

3. Please rate your level of experience in the following areas:

For each of the following items, please fill-in one number to indicate your experience. Use the following scale:

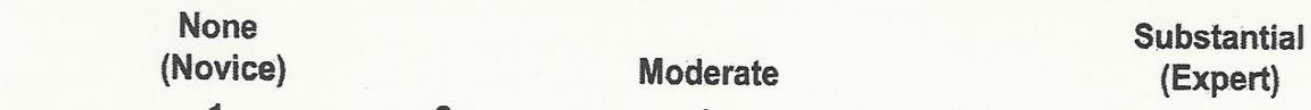

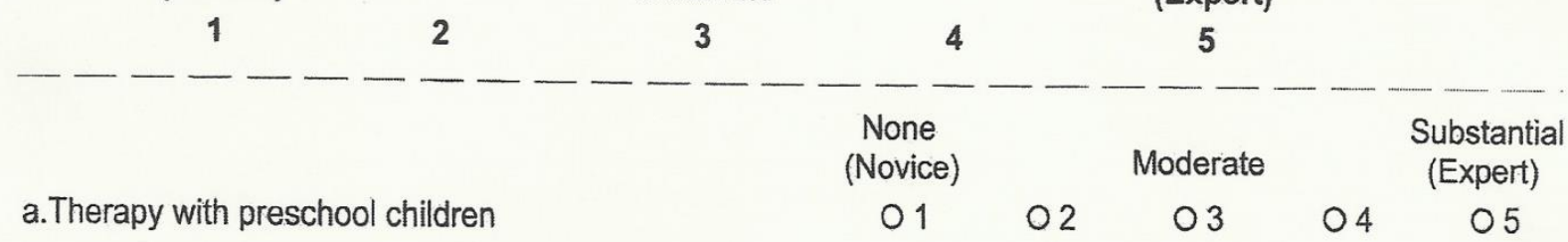
b. Assessment of child and family functioning
01
02
03
04
05
c. Cognitive Behavioral Therapy
0102
$03 \quad 04 \quad 05$
d. Family Therapy
01
02
O 3
04
05

e. Behavioral Parent Training

$\begin{array}{lllll}01 & 02 & 03 & 04 & 05\end{array}$

4. In the last 6 months, what trainings have you attended? Please list the topics of any trainings here:

a.

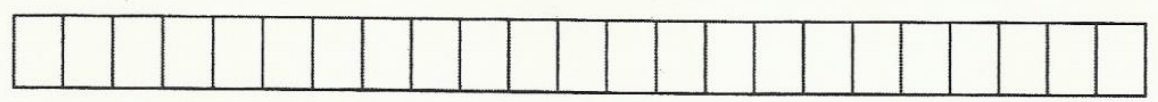

b.

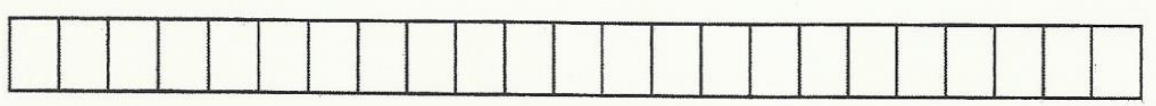

c.

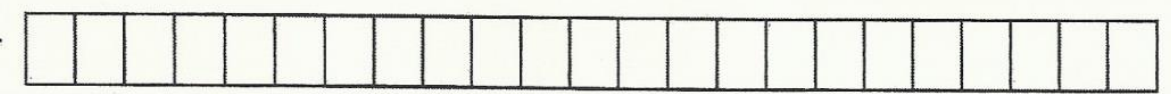

8. How long was each training (in hours)?
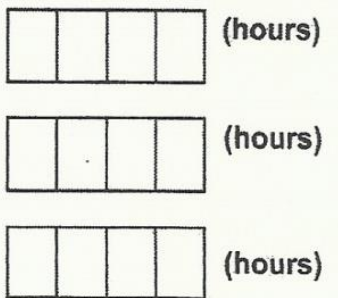


\section{Please list your current Agency, Agency Program(s), Supervisor(s), Work Contact Information,} ome Contact Information and Internet Access / Email

Agency where you will be providing PCIT:

O Devereux Community Services

O Holcomb Behavioral Health Systems

$O$ Child Guidance Resource Centers

O University Community Behavioral Health

O Alternative Community Resource Program

O Nulton Diagnostic and Treatment Center

\section{Agency Program(s):}

Primary Agency Program that you work in (Primary agency program should be the one that you do most of your work in)

OBehavioral Health Rehabilitation Services / Wraparound O Family-Based O Inpatient O Outpatient

O Partial Hospitilization O School-Based O Other, please specify:

N/A Secondary Agency Program that you work in (Bubble "N/A" if you work in only one agency program)

O OBehavioral Health Rehabilitation Services / Wraparound O Family-Based O Inpatient O Outpatient

O Partial Hospitilization O School-Based O Other, please specify:

\section{Clinical Supervisor(s): (Primary supervisor should be the direct supervisor with whom you have the most contact)} Primary Supervisor's Name (first)

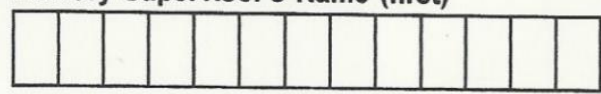

(last)

Secondary Supervisor's Name (first)

$\checkmark$

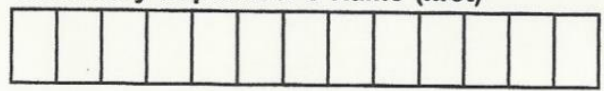

(last) (Bubble "N/A" if you only have 1 direct supervisor.)

\section{Work Contact Information:}

Work Phone
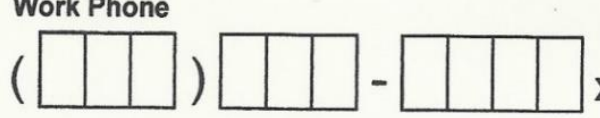

Ext. (if applicable)

$\mathbf{x}$

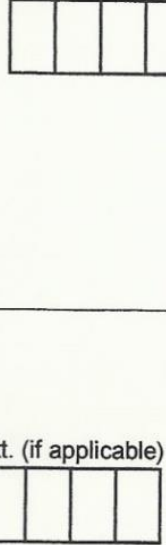

Work Email Address (ex. jsmith@companyname.com)

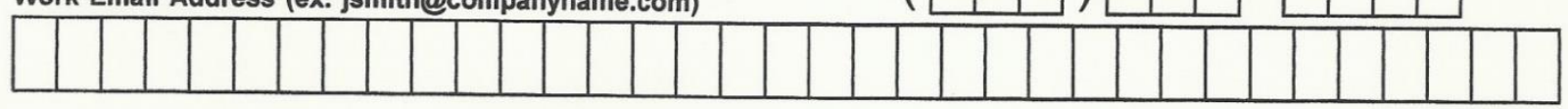

Work Cell Phone (if applicable)

Text Messages?

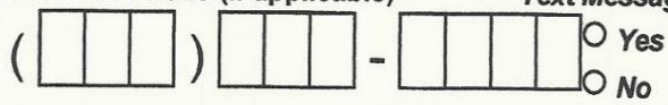

Work Pager (if applicable)

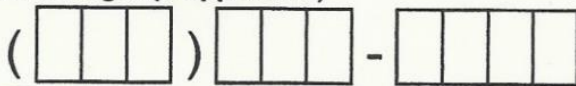


Home Contact Information:

Your Street Number \& Address

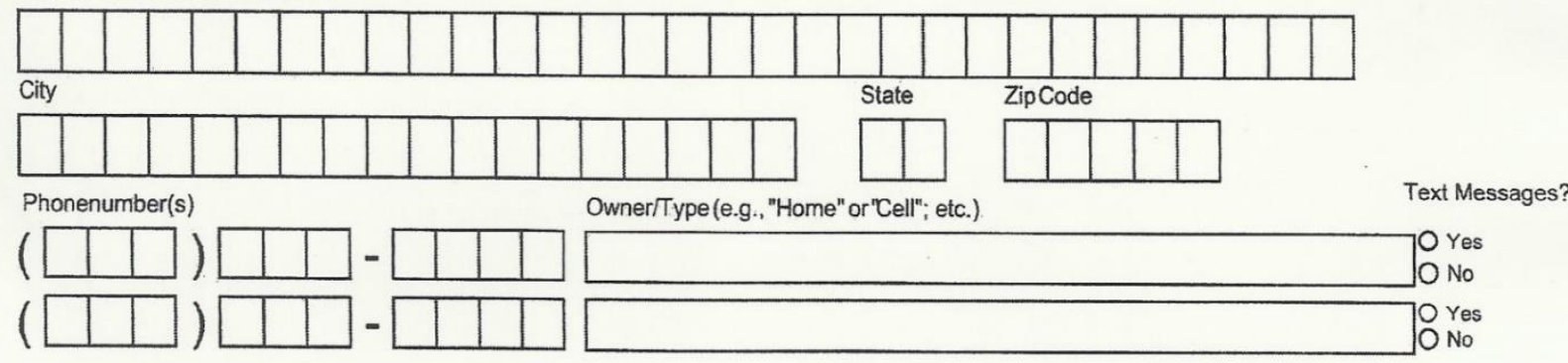

Internet Access / Email:

Do you have internet access at home? O Yes O No Do you have email access at home? O Yes NoO Email\#1: Address

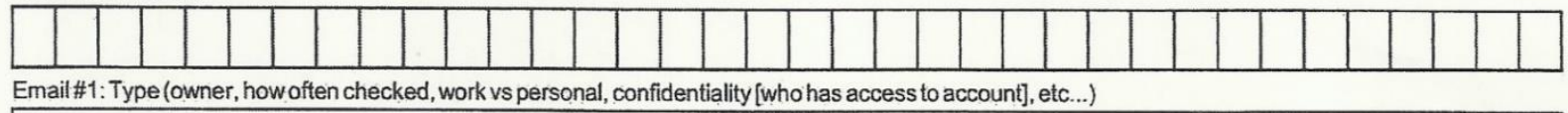
etc...)

Email \#2: Address

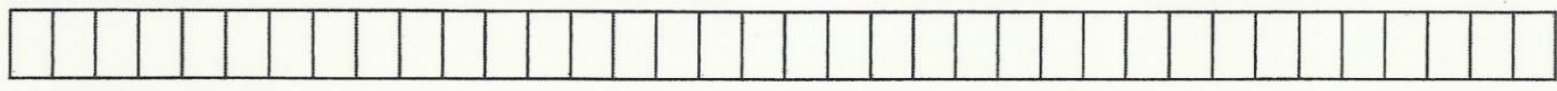

Email\#2: Type (owner, how often checked, work vs personal, confidentiality [who has access to account], etc...)

What is your preferred method of communication?

(Please check one)

O Email O Work Phone O Cell Phone O Home Phone O Text

Please provide information for another person who may help us contact you.

Person's Name (first)

(last)
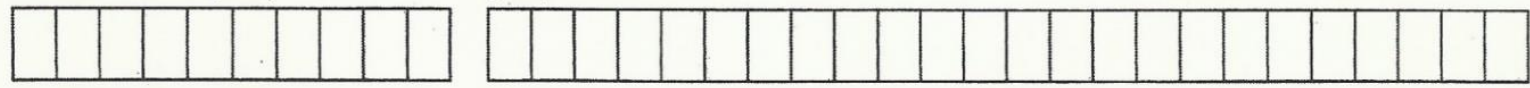

Number \& Street Address

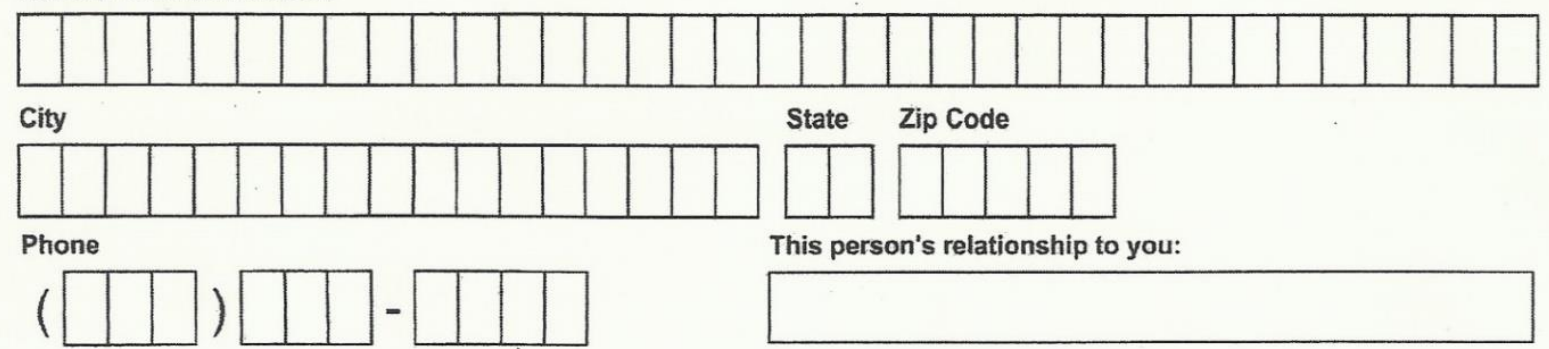

Page 4 of 28 
Participant ID

\section{Clinician Background and Contact Information Form (continued)}

How many clients are you currently treating (i.e., total number on your caseload)?

Considering all the clients on your caseload, what percentage fall into the following age ranges: (These totals should add up to be $100 \%$ )

\begin{tabular}{|l|l|}
\hline & Percentage $(\%)$ \\
\hline Under 3 years old & \\
\hline $3-5$ years old & \\
\hline $6-12$ years old & \\
\hline $13-18$ years old & \\
\hline Older than 18 years & \\
\hline
\end{tabular}

Considering all the clients on your caseload, what percentage of cases do you believe has had the following experiences? (some cases may have had multiple experiences, so the sum of all the percentages may exceed $100 \%$ )

\begin{tabular}{|l|l|}
\hline & Percentage (\%) \\
\hline Physical abuse/harsh physical discipline & \\
\hline Sexual abuse & \\
\hline Emotional abuse & \\
\hline Neglect & \\
\hline $\begin{array}{l}\text { Other child welfare concerns } \\
\text { please specify: }\end{array}$ & \\
\hline
\end{tabular}

Considering all the clients on your caseload, what percentage of cases do you believe has had the following diagnoses? (some cases may have had multiple diagnoses, so the sum of all the percentages may exceed $100 \%$ )

\begin{tabular}{|l|l|}
\hline & Percentage (\%) \\
\hline Developmental delays & \\
\hline Autism spectrum Disorder & \\
\hline $\begin{array}{l}\text { Internalizing Disorders (e.g., anxiety, } \\
\text { depression) }\end{array}$ & \\
\hline $\begin{array}{l}\text { Externalizing Disorders (e.g., disruptive } \\
\text { behavior disorders, ADHD, Conduct Disorder) }\end{array}$ & \\
\hline Learning Disorders & \\
\hline
\end{tabular}

What is the primary service area for your organization? (please check one)

$\square$ Rural

$\square$ Suburban

$\square$ Urban 
Does your organization primarily serve?

Please circle yes or no for each

\begin{tabular}{lll}
\hline Adults & Yes & No \\
\hline Young children & Yes & No \\
\hline Clients involved with child welfare & Yes & No \\
\hline Clients involved with criminal justice & Yes & No \\
\hline
\end{tabular}

Are you employed part-time or full-time at your agency? (please check one)

$\square$ Full-time

$\square$ Part-time

a. If full-time, what is your annual salary?

b. If part-time, what is the hourly rate you get paid? 


\section{Treatment Summary Report}

Return using pre-stamped envelope or fax to (412) 605-0513

First Name

Child

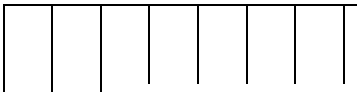

First Name

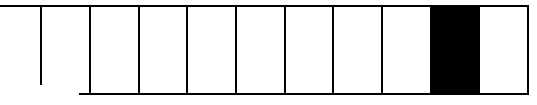

Last
Last Initial

Agency ID:

: $\quad$ Family ID:

Person

completing form

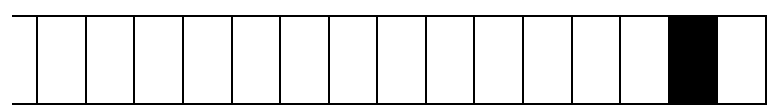

Treatment History - Who Provided Treatment For This Family?

When Family Started

Lead Clinician: First Name and Last Initial
Secondary Clinician $\quad \mathrm{NA}$ - there was no 2 nd at start

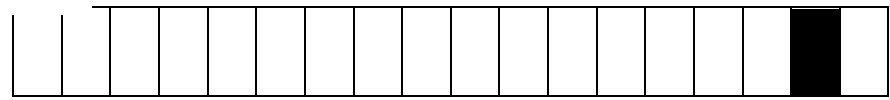

At Time of Discharge

Lead Clinician: $\quad$ First Name and Last Initial

Secondary Clinician $\quad$ NA - there was no 2 nd at discharge
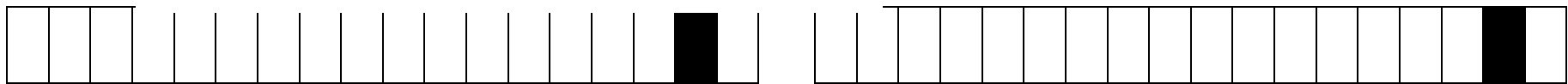

Primary Clinician (the one clinician most involved in over the entire course of treatment - please pick

on' First Name and Last Initial

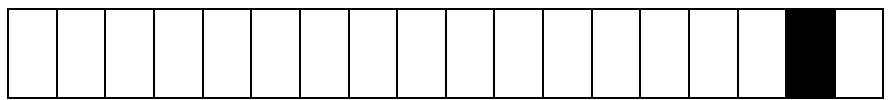

Agency name:

Please summarize this family's recent service involvement and experience with you during only this window of time. This information is confidential and will not be shared with the family, your agency, or other providers. The use of this form is for research purposes only. Thanks in advance for your help!

1. Treatment Timeline:

\section{Services Provided Log}

Please include the date for each of the activities/sessions mentioned below, OR mark if family did not complete the session.

\begin{tabular}{|l|l|l|}
\hline Activity/Session & Date:_______ & $\begin{array}{l}\text { \ family did not } \\
\text { complete this session }\end{array}$ \\
\hline $1^{\text {st }}$ Contact with the agency & & \\
\hline $1^{\text {st }}$ agency intake session & & \\
\hline
\end{tabular}




\begin{tabular}{|l|l|l|}
\hline PCIT Intake session & & \\
\hline CDI Teach & & \\
\hline PDI Teach & & \\
\hline Graduation & & \\
\hline
\end{tabular}

As you complete the rest of this form, please consider the time from the PCIT Intake session to the time you discharged the family from PCIT.

2. What was the content that was initiated for the last session the family attended?

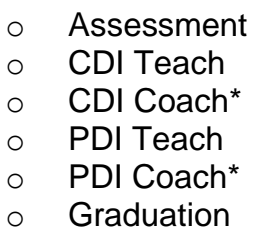

2a. If a coaching session was the last session a family attended, please specify the number (e.g., CDI Coach-8):

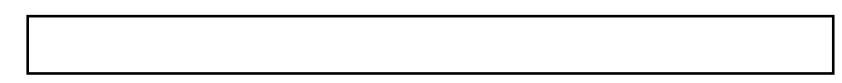

3. How many CDI Coaching Sessions did the family attend?

4. How many PDI Coach Sessions did the family attend?

If the family did not attend PDI Coach Sessions and you indicated zero for item \#4, please skip to item $\# 7$

5. If the family completed any PDI Coach Sessions, please complete the following set of questions about the time-out sequence:

Did the child ever go to the time-out chair during a clinic-based PCIT session? OYes No

Did the child ever go to the time-out back-up (e.g., time-out room, swoop \& go) during a clinic-based PCIT session?

$$
\text { OYes O No }
$$

If yes, what did you use as the time-out back-up? (Pick all that apply)

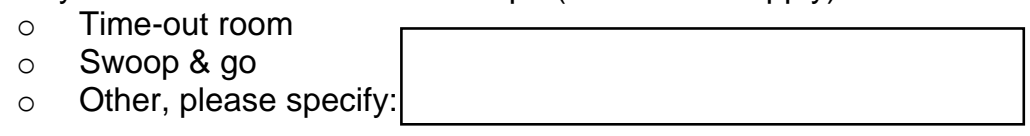

If yes, for how many sessions did the child go to the time-out back-up?

If yes, what was the average amount of time that the child spent in the time-out back-up at any one time before returning to the chair $\quad$ h the back-up)?

6. Is there anything you would like to mention about your experience with PDI generally or the time-out procedure specifically?

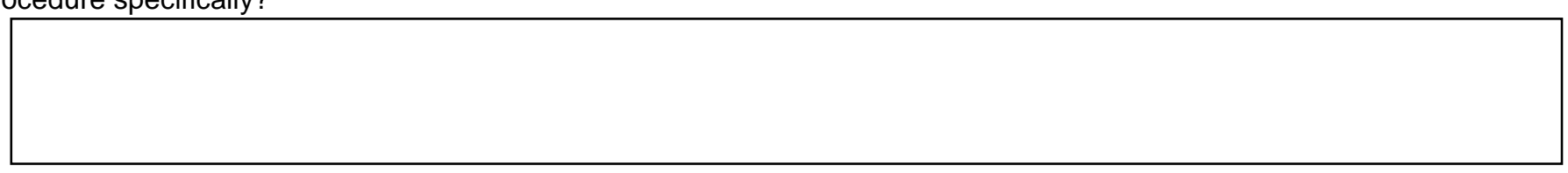

7. Please include the family Eyberg Child Behavior Inventory (ECBI) Scores below 
O I did not complete the ECBI with this family.

\section{Before PCIT Began}

What was the pre-treatment ECBI Intensity Score?

What was the pre-treatment ECBI Problem Score?

\section{After Completing Some or All of PCIT}

What was the date the last ECBI was completed?

What was the last ECBI Intensity Score?

What was the last ECBI Problem Score?

Was this final ECBI considered a post-treatment ECBI Score?

8. What is the approximate total number of hours of PCIT services that you provided to the family? (\# of hours)

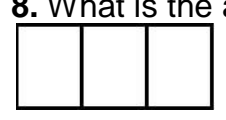

9. Over how many weeks were PCIT services provided? (\# of weeks)

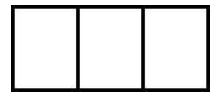

10. Which family members participated in PCIT during the above-mentioned time frame?

Fill in all that apply.
O Child/Adolescent
O Female Caregiver
O Male Caregiver
O Grandmother
O Grandfather
O Siblings

O Other (specify):

11. Please indicate all services that you or your agency provided while working with this client/family during the specified time frame. Fill in all that apply:
O PCIT
O BHRS or wraparound
O School-based counseling / consulting
O Therapeutic preschool
O Group therapy with child
O Medication for child
O Case management
O Outpatient individual therapy with child

O Outpatient family therapy

O Medication for parent

O Group therapy with parent

O Crisis in-home

O Family-based mental health services

O Family-focused/Solution-based

O Family preservation

O Other (specify): 


\section{Your Impressions about Treatment Completion}

12. Indicate if the following issues have had a negative impact on the overall course and outcome of this case:

a. Marital discord/conflict.

b. Family involvement in other treatment programs that interfere/compete with your PCIT services

c. Conflict with an outside family member/friend.

d. Conflict with work and family schedules/too busy

e. Dangerous community....

f. Parent very angry or hostile.

g. Drug/alcohol problem.....

h. Severity of parental mental health problems.

i. Limited parental cognitive skills

j. Residential instability - moves, no phone, etc.

k. Child out of the home...

I. Parent out of the home.

m. Limited child cognitive skills

n. Having to "childline" a family or report suspected abuse to child welfare

o. Domestic violence.

p. Other (specify:) 
13. Rate the caretaker's (i.e., primary adult participant's) commitment to services (e.g., attendance, participation in sessions, follow through on recommendations, completion of homework):

$\begin{array}{ccccc}\text { Very Low } & \text { Moderate } & \text { Very High } \\ 0 & 0 & 0 & 0 & 0\end{array}$

14. Please list up to $\mathbf{3}$ primary targets of treatment that you identified for the child:

Rate the level of change in the child's primary target problems/areas:

Primary target \#1: $\quad$ Got worse About the same A little better A lot better Problem resolved Noinfo

O

$\mathrm{O}$

O

O

$\mathrm{O}$

$\mathrm{O}$

O

Primary target \#2:

Primary target \#3:

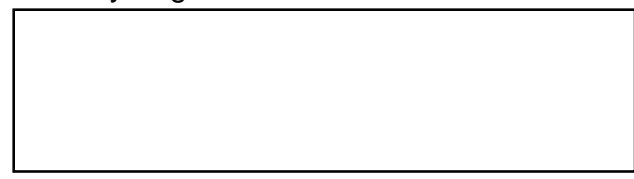

$\begin{array}{llll}0 & 0 & 0 & 0\end{array}$
15. Please list up to 3 primary targets of treatment that you identified for the parent:

Rate the level of change in the parent's primary target problems/areas:

Primary target \#1: rosalved Noinfo Got worse About the same A little better A lot better Problem

O

O

$\mathrm{O}$

O

O

Primary target \#2:

O

O

O

O

O

Primary target \#3: 
17. Overall, how much progress did the family make in treatment?

None

$\mathrm{O}$
Some

$\mathrm{O}$
A Lot

$\mathrm{O}$
O

18. Please summarize the overall disposition of the case (fill in one only):

O Case Closed: with no continuation of current service(s)

O Case Closed: with some resources/info (e.g., provider list, info on services)

O Case Closed: with recommended alternate service(s):

O Case Active: continuation of existing services only

O Case Active: continuation of existing services plus recommended:

O Uncertain of disposition as of Discharge Date - reason:

19. Case status as of Discharge Date: l_ 1 (choose one only):

O Case completed PCIT at agreed upon time

O Case left services prematurely, before an adequate or agreed upon time

20. Why were PCIT services ended? (fill in all that apply)
O Problems got better / clinical improvement
O Graduated from treatment (i.e., parent and child met mastery criteria)
O Therapist felt PCIT services were no longer needed
O Family felt that PCIT services were no longer needed
O Problem got worse / clinical deterioration; (e.g. level/type of treatment not working)
O Disinterest in PCIT / low motivation
O Non-compliance with PCIT bv patient and/or familv during sessions
O No-shows (list frequency):
O Cancellations (list frequency):
O Family or child moved / no longer available/missing
O Major crises or family emergency, including serious illness (describe):
O Limited resources / unable to attend due to time, transportation, or money
O Do not like therapy (i.e., PCIT), therapist, or other aspects of the service
O Legal problems that prevent family's participation
O Schedule conflicts
O Insurance company or policy constraints / issues
O Child removed from home
O Other (specify and also include if it is "clinician impression" or "parent report"): 
21. Indicate which, if any, of these services were recommended after discharge (fill in all that apply)
O Partial hospitalization or day treatment
O Residential treatment
O Inpatient hospitalization or day treatment
O Support group
O Community supportive services
O Administrative case management (not face-to-face)
O Intensive case management / resource coordination (face-to-face)
O Other (specify):
O Family-based
O Family-therapy
O Outpatient treatment
O BHRS (wraparound)

22. Please describe any other important details about the family's course of treatment: 


\section{PFF: Family Info}

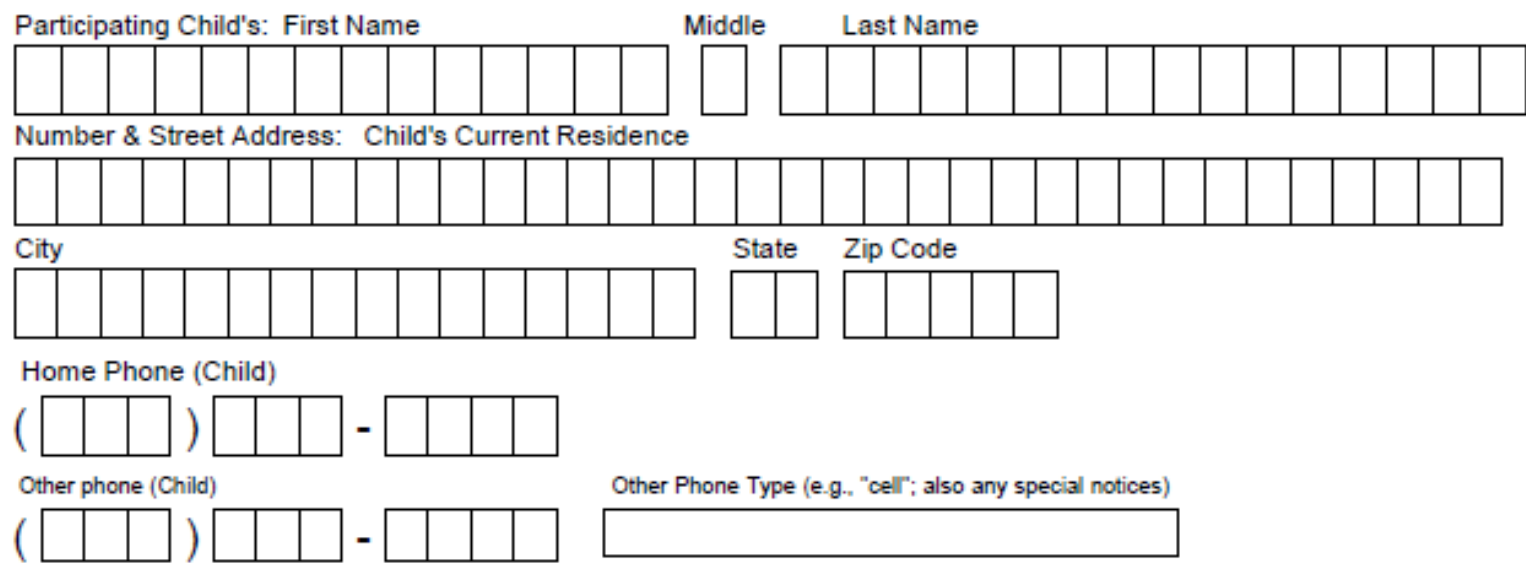

\section{School Info:}

School District (current):

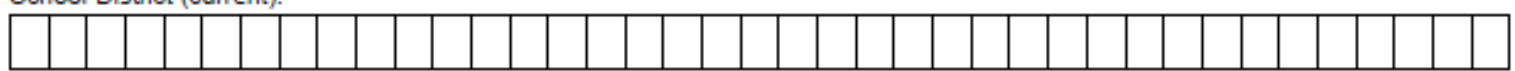

School \#1 Name (primary current school):

O Regular public school $\mathrm{O}$ Home schooled

Regular private/parochial $O$ Cyber schooled

O Approved private school $O$ Not schooled

O Tech/vocational O Other

School \#2 Name (secondary current school; if applicable):

O Regular public school $O$ Home schooled

Regular private/parochial $O$ Cyber schooled

Adult filling out this form:

Approved private school O Other

Tech/vocational

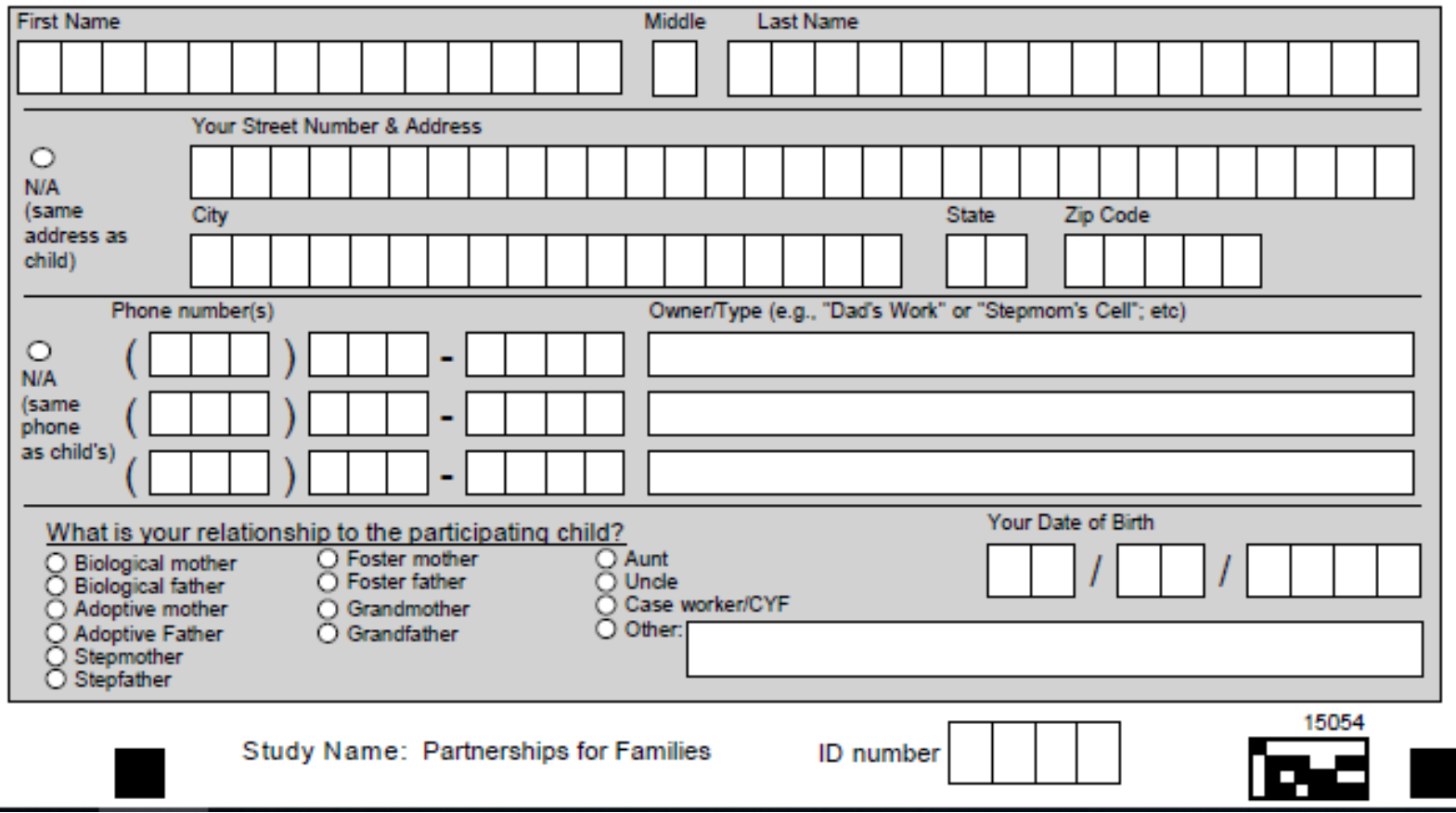



or involved with child's care:
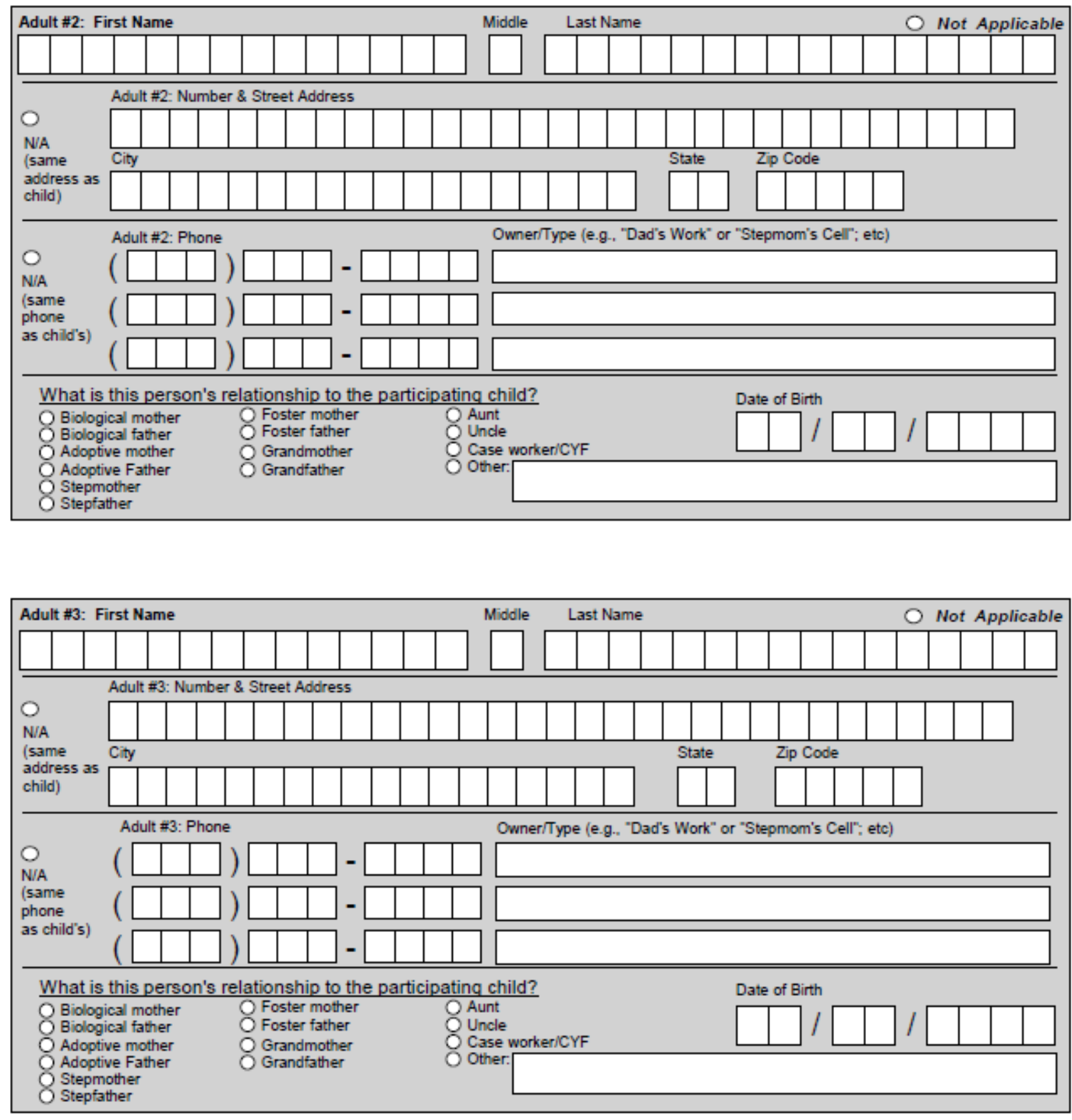
Page 3

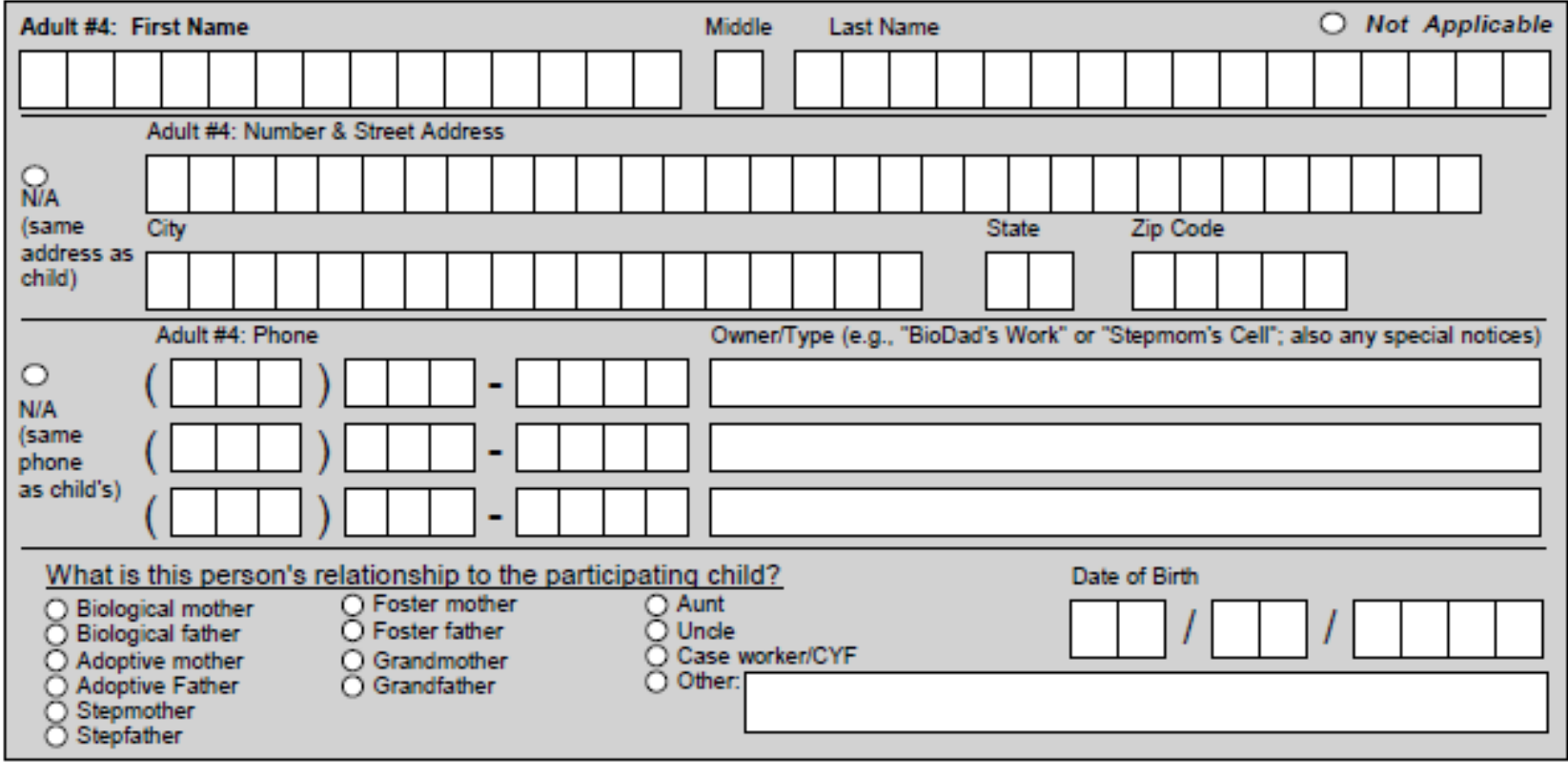

Do you have internet access at home? $\bigcirc$ Yes Do you have email access at home? $\mathrm{O}$ ?es

Email \#1: Address

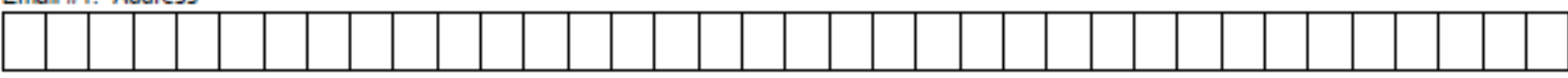

Email \#1: Type (owner, how often checked, work vs personal, confidentiality [who has access to account], etc...)

Email \#2: Address

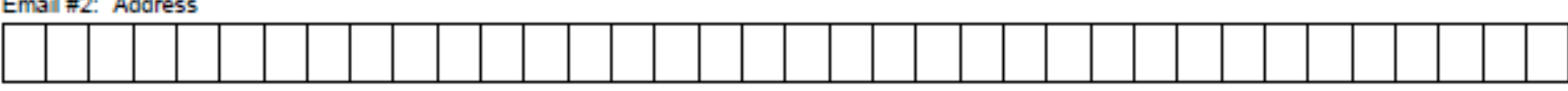

Email \#2: Type (owner, how often checked, work vs personal, confidentiality [who has access to account], etc...)

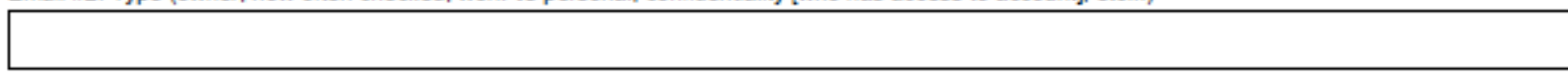

\section{Placement / Residential Changes}

Has this child lived in the same place throughout the past year (or since the last assessment)? Y Yes No

Is this child currently in a placement arranged by someone outside of the family $\bigcirc$ Yes $\bigcirc$ No

(e.g., child welfare system, court, etc...)?

If Yes, where is the child currently placed,

and how long has he/she been there?

What was the reason for the placement?

If child is Not Currently in placement, has he/she been in a placement arranged by someone outside of the family (e.g., child welfare system, court, etc...) at any time in the past year (or since the last assessment)?

If Yes, where was the child placed, and how long was he/she there?

What was the reason for the placement? 


\section{ECBI Evbers Child ECBI. Beharoor rnventory"}

\section{Parent Rating Form by Sheila Eyberg, PhD}

Your Name Relationship to Child Today's Date

Child's Name Child's Gender Child's Date of Birth

Directions: Below are a series of phrases that describe children's behavior. Please (1) circle the number describing how often the behavior currently occurs with your child, and (2) circle either "yes" or "no" to indicate whether the behavior is currently a problem for you.

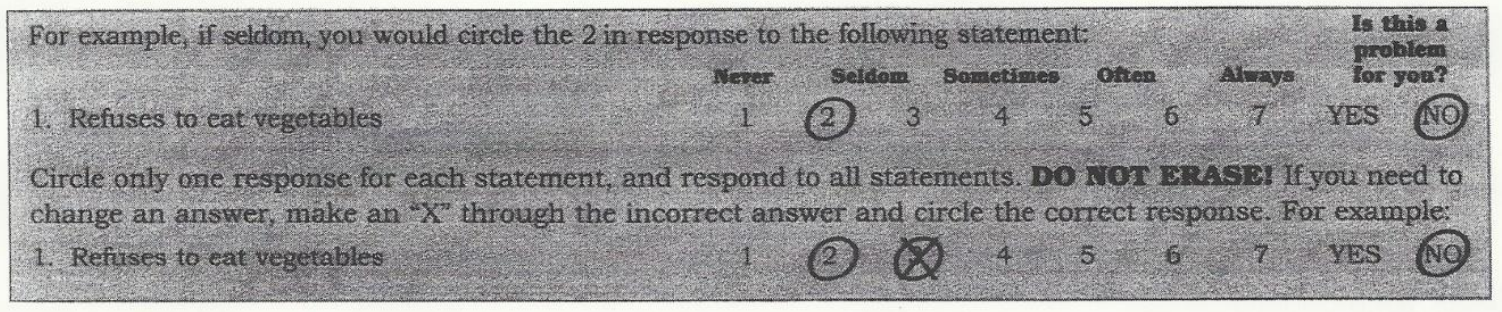

\begin{tabular}{|c|c|c|c|c|c|c|c|c|c|}
\hline \multirow[b]{3}{*}{ 1. Dawdles in getting dressed } & \multicolumn{7}{|c|}{ How often does this occur with your child? } & \multicolumn{2}{|c|}{$\begin{array}{l}\text { Is this a } \\
\text { problem } \\
\text { for you? }\end{array}$} \\
\hline & \multirow{2}{*}{$\begin{array}{c}\text { Never } \\
1\end{array}$} & \multicolumn{2}{|c|}{ Seldom } & \multirow{2}{*}{$\begin{array}{c}\text { Sometimes } \\
4\end{array}$} & \multicolumn{2}{|c|}{ Often } & \multirow{2}{*}{$\begin{array}{c}\text { Always } \\
7\end{array}$} & \multirow[b]{2}{*}{ YES } & \multirow[b]{2}{*}{ NO } \\
\hline & & 2 & 3 & & 5 & 6 & & & \\
\hline 2. Dawdles or lingers at mealtime & 1. & 2 & 3 & 4. & 5. & 6. & ? & YES & No \\
\hline 3. Has poor table manners & 1 & 2 & 3 & 4 & 5 & 6 & 7 & YES & No \\
\hline 4. Refuses to eat food presented & 1 & 2. & 3 & 4 & 5 & 6 & 7 & YeS & No \\
\hline 5. Refuses to do chores when asked & 1 & 2 & 3 & 4 & 5 & 6 & 7 & YES & NO \\
\hline 6. Slow in getting ready for bed & 1. & 2 & 3. & 4 & 5 & 6. & 7 & YES & NO \\
\hline 7. Refuses to go to bed on time & 1 & 2 & 3 & 4 & 5 & 6 & 7 & YES & NO \\
\hline 8. Does not obey house rules on own & 1 & 2 & 3. & 4 & 5 & 6 & 7. & YES & NO \\
\hline 9. Refuses to obey until threatened with punishment & 1 & 2 & 3 & 4 & 5 & 6 & 7 & YES & No \\
\hline 10. Aots defiant when told to do something & 1. & 2 & 3. & 4 & 5 & 6 & 7 & YES & nO \\
\hline 11. Argues with parents about rules & 1 & 2 & 3 & 4 & 5 & 6 & 7 & YES & NO \\
\hline 12. Gets angy when doesn't get own way & 1. & 2 & 3 & 4 & 5 & 6. & 7. & YES & No \\
\hline 13. Has temper tantrums & 1 & 2 & 3 & 4 & 5 & 6 & 7 & YES & NO \\
\hline 14. Sasses adults & 1. & 2 & 3. & 4 & 5 & 6 & 7 & YES & No. \\
\hline \multirow[t]{2}{*}{ 15. Whines } & 1 & 2 & 3 & 4 & 5 & 6 & 7 & YES & NO \\
\hline & & & & & & tbetotals & & & \\
\hline
\end{tabular}

PAR - 16204 N. Florida Ave. • Lutz, FL $33549 \cdot 1.800 .331 .8378$ - www.parinc.com

Copyright 1998,1999 by PAR. All rights reserved. May not be reproduced in whole or in part in any form or by any means without written permission of PAR. This form is printed in burgundy ink on white paper. Any other version is unauthorized.

9

Reorder $\because R O-4211$

Printed in the U.S.A. WARNING! PHOTOCOPYING OR DUPLICATION OF THIS FORM WITHOUT PERMISSION IS A VIOLATION OF COPYRIGHT LAWS. 


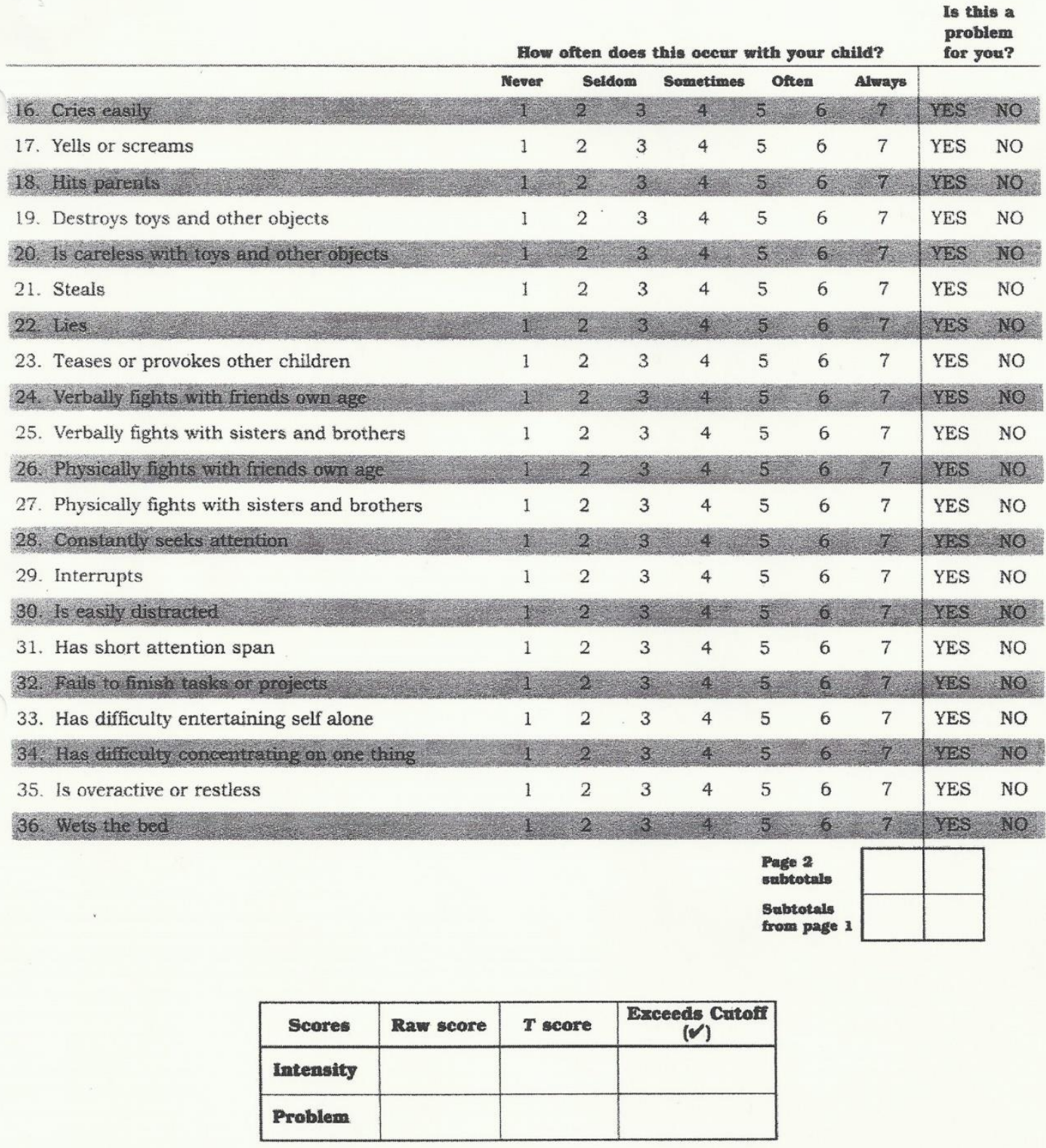

\section{Comments:}


The University of New Orleans

Alabama Parenting Questionnaire - Short Form (APQ-9)

(Parent Form)

Child's Name:

ID\#

Parent Completing Form (circle one): Mother

Father

Other:

Instructions: The following are a number of statements about your family. Please rate each item as to how often it TYPICALLY occurs in your home. Possible answers are: Never (1), Almost Never (2), Sometimes (3), Often (4), Always (5). PLEASE ANSWER ALL ITEMS.

Never

1

1. You let your child know when he/she is doing a good job with something

2. You threaten to punish your child and then do not actually punish him/her

3. Your child fails to leave you a note or to let you know where he/she is going

4. Your child talks you out of being punished after he/she has done something wrong

5. Your child stays out in the evening after the time he/she is supposed to be home

6. You compliment your child after he/she has done something well

7. You praise your child if he/she behaves well

8. Your child is out with friends you don't know

9. You let your child out of a punishment early (like lift restrictions earlier than you originally said)

1

1

1

1

1

1

1

1

\section{Almost \\ Sometimes \\ Often \\ Never}

2

3

4

2

3

4

2

3

4

2

3

4

2

3

4

2

3

4

2

3

4

2

3

4

2

3

4
5

5

5

5

5

5

5

5

Always

5

5

5




\section{Appendix B: Tables and Figures}

Figure 1

Flow of Video Selection for Participant Inclusion

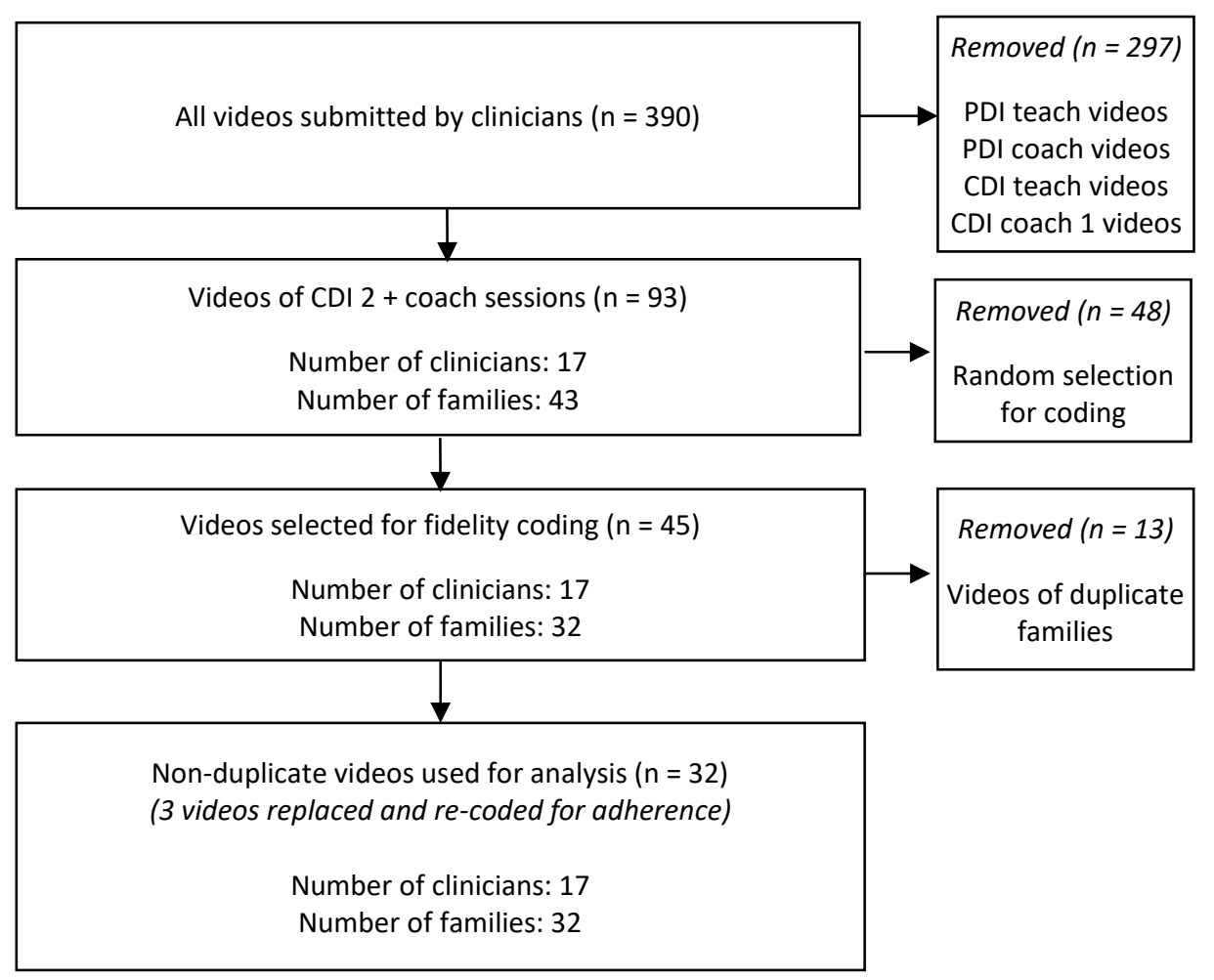


Table 1

Child, Parent, and Therapist Characteristics as a Percentage of the Sample (Parent Study Data in Parentheses)

\begin{tabular}{|c|c|c|c|}
\hline Characteristic & $\begin{array}{c}\text { Child } \\
(n=32)\end{array}$ & $\begin{array}{l}\text { Parent } \\
(n=32)\end{array}$ & $\begin{array}{c}\text { Clinician } \\
(n=17)\end{array}$ \\
\hline \multicolumn{4}{|l|}{ Race } \\
\hline White/Caucasian & $84.38(78.30)$ & $84.38(78.80)$ & $100.00(91.00)$ \\
\hline Black/African-American & $12.50(28.80)$ & $12.50(20.70)$ & $0.00 \quad(5.00)$ \\
\hline Asian & $0.00 \quad(0.44)$ & $0.00 \quad(0.44)$ & $0.00 \quad(1.00)$ \\
\hline Unknown/Other & $3.13(1.75)$ & 3.13 (1.32) & $0.00 \quad(3.00)$ \\
\hline Non-Hispanic & $87.50(82.80)$ & $90.63(90.00)$ & $100.00(92.00)$ \\
\hline Female & $25.00(31.00)$ & $90.63(96.00)$ & $81.25(84.00)$ \\
\hline \multicolumn{4}{|l|}{ Highest Education Level } \\
\hline$<7^{\text {th }}$ Grade & & $3.13(2.70)$ & \\
\hline $9^{\text {th }}$ Grade & & $3.13(1.60)$ & \\
\hline Some High School & & $23.44 \quad(9.00)$ & \\
\hline High School/GED & & $23.44(38.80)$ & \\
\hline Some College & & $19.53(18.10)$ & \\
\hline Associate's & & $3.13(10.60)$ & \\
\hline Bachelor's & & $11.72(5.90)$ & \\
\hline Graduate/Professional & & $12.50(13.30)$ & \\
\hline Master's & & & $88.24(92.00)$ \\
\hline Doctoral & & & $11.76(8.00)$ \\
\hline \multicolumn{4}{|l|}{ Employment } \\
\hline Full Time & & $54.59(44.40)$ & \\
\hline Part Time & & $3.91(15.70)$ & \\
\hline Unemployed/Retired & & $35.16(39.90)$ & \\
\hline \multicolumn{4}{|l|}{ Marital Status } \\
\hline Single & & $37.50(50.50)$ & \\
\hline Divorced & & $21.88(10.80)$ & \\
\hline Separated & & $11.72(7.00)$ & \\
\hline Married & & $28.91(31.70)$ & \\
\hline \multicolumn{4}{|l|}{ Income } \\
\hline$<\$ 14,999$ & & $42.19(47.30)$ & \\
\hline$\$ 15,000-\$ 29,999$ & & $27.34(26.90)$ & \\
\hline$\$ 30,000-\$ 49,999$ & & $9.38 \quad(8.80)$ & \\
\hline$\$ 50,000-\$ 74,999$ & & $7.03(6.60)$ & \\
\hline$>\$ 75,000$ & & $14.06(10.40)$ & \\
\hline Behavioral Health Diagnosis & $68.75(68.90)$ & & \\
\hline Behavioral Health Medication & $42.97(29.20)$ & & \\
\hline Physical Health Diagnosis & $58.59(44.30)$ & & \\
\hline Completed CDI Teach & $90.63(90.20)$ & $90.63(90.20)$ & \\
\hline Completed PDI Teach & $43.75(41.50)$ & $43.75(41.50)$ & \\
\hline Graduated & $34.38(30.30)$ & $34.38(30.30)$ & \\
\hline
\end{tabular}


Table 2

Descriptive Statistics and Correlations among Variables

\begin{tabular}{|c|c|c|c|c|c|c|c|c|}
\hline Variable & $n$ & $M(S D)$ & Range & 1 & 2 & 3 & 4 & 5 \\
\hline 1. FCCS-CDI & 112 & $0.56(0.32)$ & $0.00-1.00$ & -- & .13 & $.29 *$ & $.38 *$ & $.22 *$ \\
\hline 2. TIC & 128 & $0.70(0.25)$ & $0.00-1.00$ & .13 & -- & .09 & .17 & -.14 \\
\hline 3. ECBI Intensity & 90 & $131.97(49.21)$ & $36.00-239.00$ & $.29 *$ & .09 & -- & $.79 * *$ & .11 \\
\hline 0 Months & 29 & $162.31(39.72)$ & $66.00-239.00$ & & & & & \\
\hline 3 Months & 19 & $134.84(50.78)$ & $36.00-228.00$ & & & & & \\
\hline 6 Months & 20 & $114.25(45.90)$ & $43.00-208.00$ & & & & & \\
\hline 12 Months & 22 & $105.59(41.65)$ & $39.00-198.00$ & & & & & \\
\hline 4. ECBI Problem & 81 & $18.06(10.92)$ & $0.00-35.00$ & $.38^{*}$ & .17 & $.79 * *$ & -- & .04 \\
\hline 0 Months & 28 & $22.57(8.90)$ & $4.00-35.00$ & & & & & \\
\hline 3 Months & 18 & $19.00(11.10)$ & $0.00-34.00$ & & & & & \\
\hline 6 Months & 19 & $15.00(11.04)$ & $0.00-35.00$ & & & & & \\
\hline 12 Months & 16 & $12.75(11.26)$ & $0.00-32.00$ & & & & & \\
\hline $\begin{array}{l}\text { 5. APQ-9 Positive } \\
\text { Parenting }\end{array}$ & 92 & $13.32(1.89)$ & $7.00-15.00$ & $.22 *$ & -.14 & .11 & .04 & -- \\
\hline 0 Months & 30 & $12.93(2.13)$ & $8.00-15.00$ & & & & & \\
\hline 3 Months & 19 & $13.47(1.81)$ & $9.00-15.00$ & & & & & \\
\hline 6 Months & 21 & $13.38(2.04)$ & $7.00-15.00$ & & & & & \\
\hline 12 Months & 22 & $13.64(1.47)$ & $11.00-15.00$ & & & & & \\
\hline
\end{tabular}

Note. The mean, standard deviation, and range of scores for each outcome are reported at each assessment time point. Variation in sample size for outcome scales reflects number of parents who reported outcomes at each time-point. FCCS-CDI = FIRST Coach Coding System for Child-Direction Interaction; TIC = Treatment Integrity Checklist; ECBI = Eyberg Child Behavior Inventory Problem Scale; APQ-9 = Alabama Parenting Questionnaire, Short Form. $*=p<.05, * *=p<.001$ 
Table 3

Fixed Effects (Top) and Random Effects (Bottom) for Three-Level Model of Fidelity Predictors on Behavior Problem Intensity, Behavior Problem Frequency, and Positive Parenting

\begin{tabular}{|c|c|c|c|c|c|}
\hline Estimate & Coefficient & $S E$ or $S D$ & $t$ or $X^{2}$ & $d f$ & $p$ \\
\hline \multicolumn{6}{|c|}{ Fixed Effects } \\
\hline \multicolumn{6}{|l|}{ ECBI Intensity at intercept } \\
\hline Mean level & 112.18 & 33.59 & 3.34 & 10 & .007 \\
\hline Adherence & 25.66 & 42.81 & 0.60 & 10 & .562 \\
\hline Competence & 45.52 & 33.57 & 1.36 & 10 & .205 \\
\hline \multicolumn{6}{|l|}{ Growth in ECBI Intensity } \\
\hline Mean rate of change & -7.32 & 2.50 & -2.93 & 10 & .015 \\
\hline Adherence & 6.70 & 3.28 & 2.04 & 10 & .069 \\
\hline Competence & -3.97 & 2.55 & -1.56 & 10 & .150 \\
\hline \multicolumn{6}{|l|}{ ECBI Problem at intercept } \\
\hline Mean level & 6.88 & 5.65 & 1.22 & 10 & .251 \\
\hline Adherence & 7.10 & 7.14 & 1.00 & 10 & .343 \\
\hline Competence & 16.36 & 5.84 & 2.80 & 10 & .019 \\
\hline \multicolumn{6}{|l|}{ Growth in ECBI Problem } \\
\hline Mean rate of change & -1.84 & 0.72 & -2.54 & 10 & .029 \\
\hline Adherence & 2.07 & 0.95 & 2.18 & 10 & .054 \\
\hline Competence & -1.03 & 0.71 & -1.45 & 10 & .179 \\
\hline \multicolumn{6}{|c|}{ APQ-9 Positive Parenting at intercept } \\
\hline Mean level & 1.01 & 0.64 & 1.58 & 10 & .144 \\
\hline Adherence & 0.41 & 0.83 & 0.50 & 10 & .629 \\
\hline Competence & -0.49 & 0.64 & -0.76 & 10 & .464 \\
\hline \multicolumn{6}{|c|}{ Growth in APQ Positive Parenting } \\
\hline Mean rate of change & 0.11 & 0.07 & 1.57 & 10 & .147 \\
\hline Adherence & -0.13 & 0.09 & -1.42 & 10 & .187 \\
\hline Competence & -0.05 & 0.07 & -0.66 & 10 & .525 \\
\hline \multicolumn{6}{|c|}{ Random Effects } \\
\hline \multicolumn{6}{|l|}{ ECBI Intensity } \\
\hline Level 1 & 664.70 & 25.78 & & & \\
\hline Intercept at Level 2 & 821.87 & 28.67 & 24.51 & 8 & .002 \\
\hline Slope at Level 2 & 0.01 & 0.11 & 20.68 & 8 & .008 \\
\hline Intercept at Level 3 & 340.04 & 18.44 & 20.19 & 10 & .027 \\
\hline Slope at Level 3 & 0.15 & 0.38 & 10.16 & 10 & .427 \\
\hline \multicolumn{6}{|l|}{ ECBI Problem } \\
\hline Level 1 & 33.01 & 5.75 & & & \\
\hline Intercept at Level 2 & 27.14 & 5.21 & 18.46 & 7 & .010 \\
\hline Slope at Level 2 & 0.09 & 0.30 & 11.10 & 7 & .134 \\
\hline Intercept at Level 3 & 1.14 & 1.07 & 6.90 & 10 & $>.500$ \\
\hline Slope at Level 3 & 0.01 & 0.12 & 18.92 & 10 & .041 \\
\hline
\end{tabular}


APQ-9 Positive Parenting

Level 1

Intercept at Level 2

Slope at Level 2

Intercept at Level 3

Slope at Level 3

0.38

0.45

0.001

0.001

0.001
0.61

0.67

0.05

0.05

0.01
28.65

11.79

10.99

13.75
8

8

10

10
$<.001$

.160

.358

.184

Note. Intercepts represent time at 0 months, i.e., the intake session. Growth estimates represent the slope of change per month after the intake session. Level 1 random effects represent variability across time (within family).Level 2 random effects represent variability across families (within clinicians). Level 3 random effects represent variability across clinicians. FCCSCDI = FIRST Coach Coding System for Child-Direction Interaction; TIC $=$ Treatment Integrity Checklist; ECBI = Eyberg Child Behavior Inventory Problem Scale; APQ-9 = Alabama Parenting Questionnaire, Short Form. 
Table 4

Fixed Effects (Top) and Random Effects (Bottom) for Models of Adherence-Competence Interaction on Behavior Problem Intensity, Behavior Problem Frequency, and Positive Parenting

\begin{tabular}{|c|c|c|c|c|c|}
\hline Estimate & Coefficient & $S E$ or $S D$ & $t$ or $X^{2}$ & $D f$ & $p$ \\
\hline \multicolumn{6}{|c|}{ Fixed Effects } \\
\hline \multicolumn{6}{|l|}{ ECBI Intensity at intercept } \\
\hline Mean level & 160.90 & 8.63 & 18.65 & 9 & $<.001$ \\
\hline Adherence & 122.54 & 148.39 & 0.83 & 9 & .430 \\
\hline Competence & 179.56 & 198.87 & 0.90 & 9 & .390 \\
\hline Interaction & -159.14 & 233.67 & -0.68 & 9 & .513 \\
\hline \multicolumn{6}{|l|}{ Growth in ECBI Intensity } \\
\hline Mean level & -4.54 & 0.67 & -6.78 & 9 & $<.001$ \\
\hline Adherence & 5.40 & 12.12 & 0.45 & 9 & .667 \\
\hline Competence & -5.81 & 15.90 & -0.37 & 9 & .723 \\
\hline Interaction & 2.13 & 18.91 & 0.11 & 9 & .912 \\
\hline \multicolumn{6}{|l|}{ ECBI Problem at intercept } \\
\hline Mean level & 22.68 & 1.42 & 15.96 & 9 & $<.001$ \\
\hline Adherence & 43.50 & 25.14 & 1.73 & 9 & .118 \\
\hline Competence & 67.51 & 34.05 & 1.98 & 9 & .079 \\
\hline Interaction & -59.85 & 39.52 & -1.51 & 9 & .164 \\
\hline \multicolumn{6}{|l|}{ Growth ECBI Problem } \\
\hline Mean level & -0.83 & 0.19 & -4.45 & 9 & .002 \\
\hline Adherence & 3.43 & 3.39 & 1.01 & 9 & .338 \\
\hline Competence & 0.63 & 4.30 & 0.15 & 9 & .886 \\
\hline Interaction & -2.17 & 5.22 & -0.42 & 9 & .687 \\
\hline \multicolumn{6}{|c|}{ APQ-9 Positive Parenting at intercept } \\
\hline Mean level & 1.08 & 0.16 & 6.77 & 9 & $<.001$ \\
\hline Adherence & 5.60 & 2.79 & 2.00 & 9 & .076 \\
\hline Competence & 6.60 & 3.73 & 1.77 & 9 & .111 \\
\hline Interaction & -8.45 & 4.38 & -1.93 & 9 & .086 \\
\hline \multicolumn{6}{|c|}{ Growth in APQ-9 Positive Parenting } \\
\hline Mean level & -0.02 & 0.02 & -1.15 & 9 & .278 \\
\hline Adherence & -0.23 & 0.34 & -0.67 & 9 & .522 \\
\hline Competence & -0.18 & 0.45 & -0.49 & 9 & .702 \\
\hline Interaction & 0.15 & 0.15 & 0.27 & 9 & .791 \\
\hline
\end{tabular}

ECBI Intensity

Level 1

Intercept at Level 2

Slope at Level 2

Intercept at Level 3

Slope at Level 3

ECBI Problem
Random Effects

$\begin{array}{ccccc}664.20 & 25.77 & & & \\ 845.24 & 29.07 & 24.55 & 8 & .002 \\ 0.02 & 0.13 & 20.64 & 8 & .008 \\ 268.40 & 16.38 & 18.95 & 9 & .025 \\ 0.16 & 0.39 & 10.03 & 9 & .348\end{array}$


Level 1

Intercept at Level 2

Slope at Level 2

Intercept at Level 3

Slope at Level 3

APQ-9 Positive Parenting

Level 1

Intercept at Level 2

Slope at Level 2

Intercept at Level 3

Slope at Level 3
32.16

24.18

0.10

0.02

0.00

0.37

0.37

0.001

0.001

0.001
5.67

4.92

0.32

0.15

0.03

0.61

0.61

0.05

0.02

0.001
18.89

11.24

6.37

18.91

28.58

12.45

8.68

13.56
.009

.128

$>.500$

$9 \quad .026$

Note. Intercepts represent time at 0 months, i.e., the intake session. Growth estimates represent the slope of change per month after the intake session. Interaction represents the interaction term adherence $\mathrm{x}$ competence. Level 1 random effects represent variability across time (within family).Level 2 random effects represent variability across families (within clinicians). Level 3 random effects represent variability across clinicians. FCCS-CDI = FIRST Coach Coding System for Child-Direction Interaction; TIC = Treatment Integrity Checklist; ECBI = Eyberg Child Behavior Inventory Problem Scale; APQ-9 = Alabama Parenting Questionnaire, Short Form. 
Figure 2

Change Behavior Problem Intensity over Time at Lower and Upper Quartile Values of Adherence and Coaching Competence

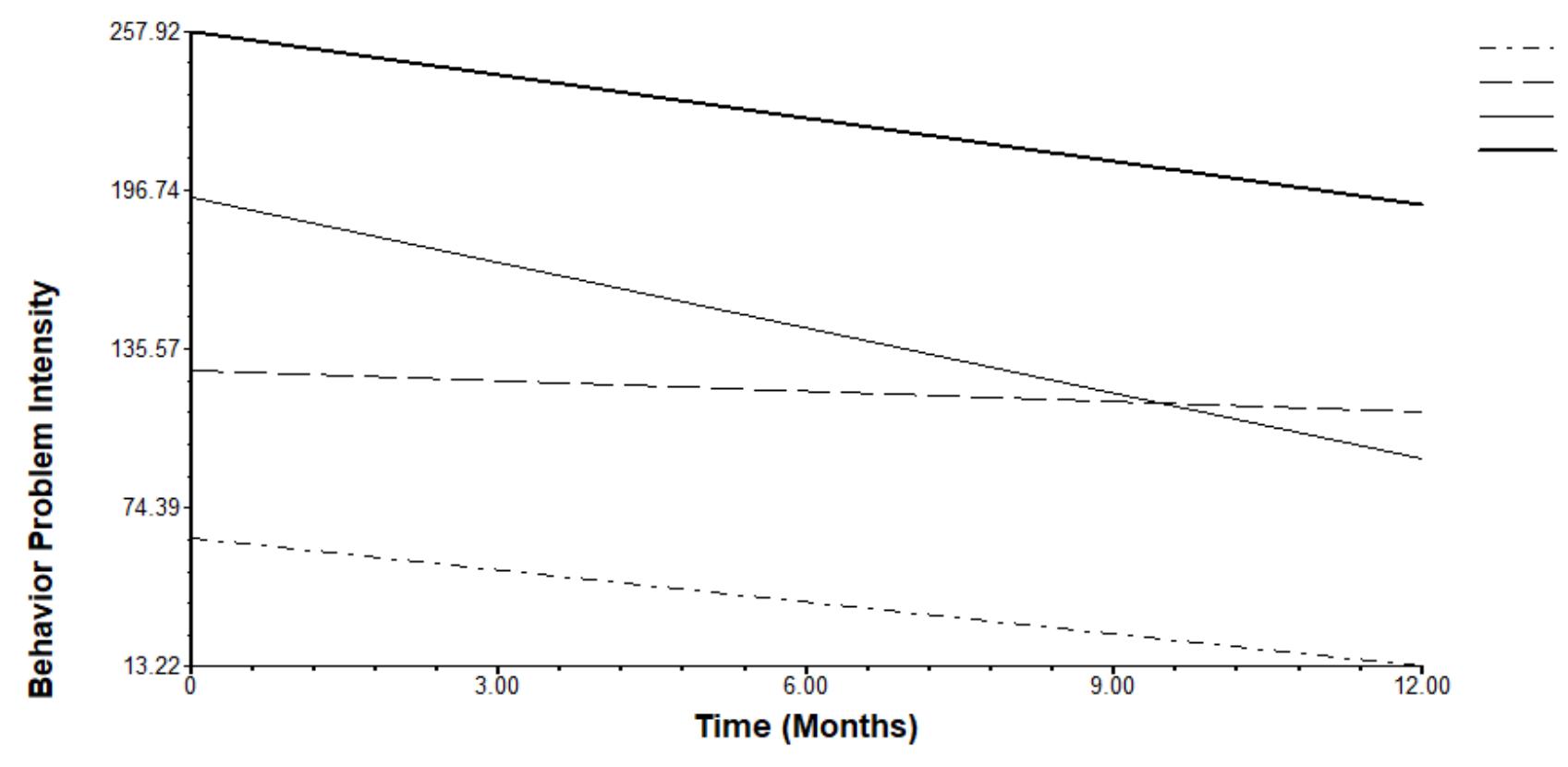

COMPETENCE $=-0.343$ ADHERENCE $=-0.296$ COMPETENCE $=-0.343$, ADHERENCE $=0.229$ COMPETENCE $=0.384$, ADHERENCE $=-0.296$ COMPETENCE $=0.384, \mathrm{ADHERENCE}=0.229$ 
Figure 3

Change Behavior Problem Frequency over Time at Lower and Upper Quartile Values of Adherence and Coaching Competence

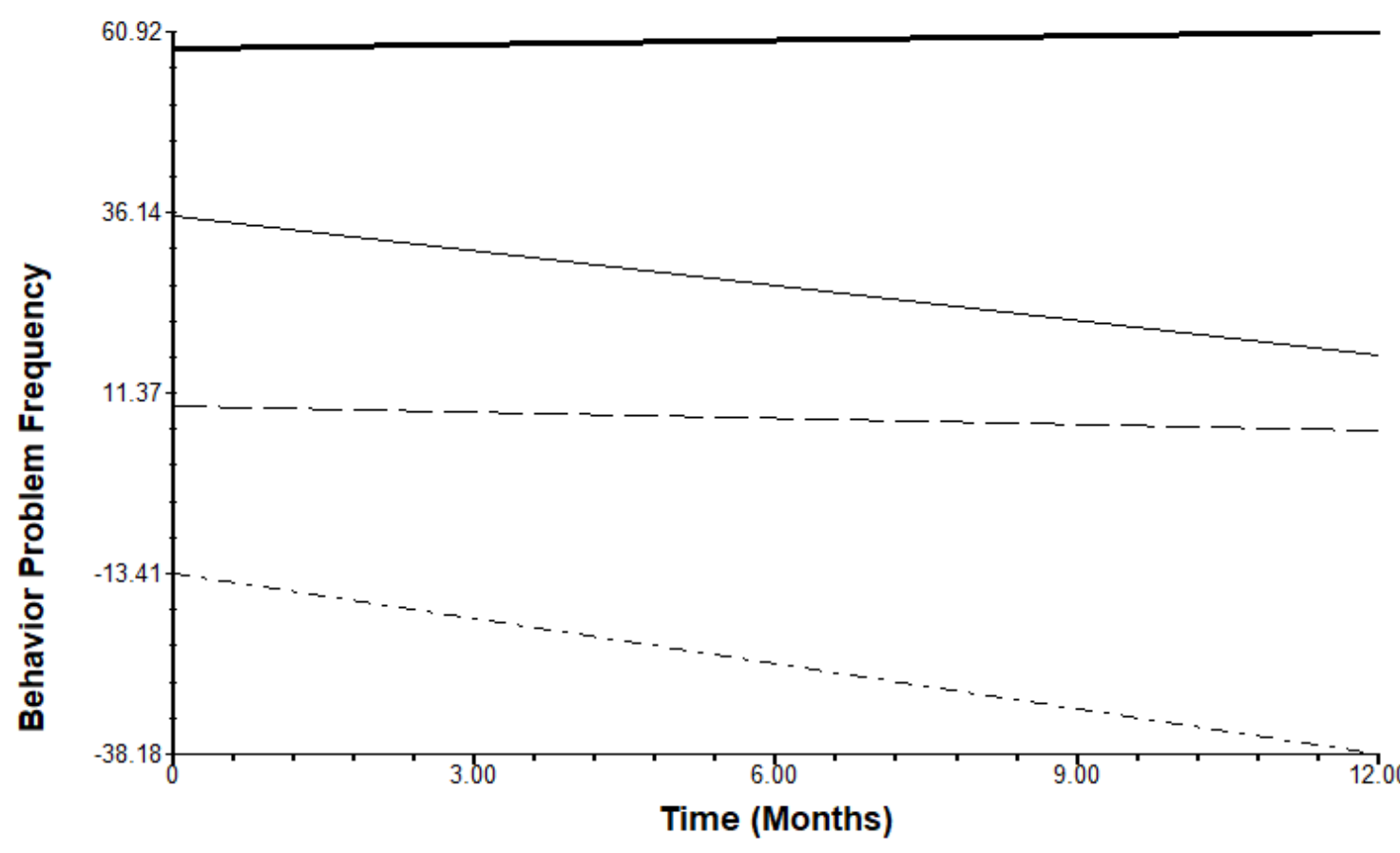

COMPETENCE $=-0.343$, ADHERENCE $=-0.296$ COMPETENCE $=-0.343$, ADHERENCE $=0.229$ COMPETENCE $=0.384, \mathrm{ADHERENCE}=-0.296$ COMPETENCE $=0.384, \mathrm{ADHERENCE}=0.229$ 
Figure 4

Change Positive Parenting over Time at Lower and Upper Quartile Values of Treatment Adherence and Coaching Competence

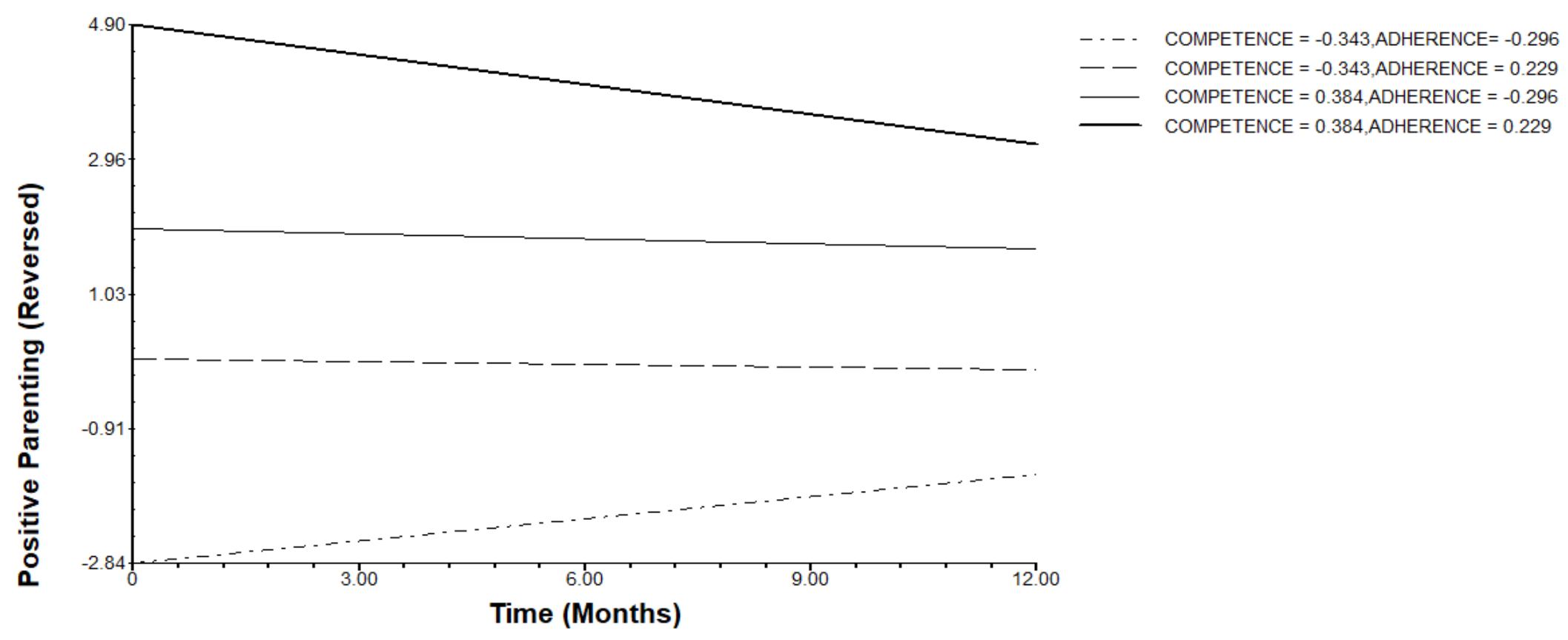

